\title{
LA DIMENSIÓN TERRITORIAL DE LA RESIDENCIALIDAD EN LAS ÁREAS TURISTIICAS DE CANARIAS $^{1}$
}

\author{
Moisés R. Simancas Cruz \\ Juan Israel García Cruz \\ Departamento de Geografía. Universidad de La Laguna \\ msimancas@ull.es, jgarciac@ull.edu.es
}

\section{RESUMEN}

La residencialidad, temporal por razones de ocio o permanente no turística, se está consolidando como un elemento básico de la estructura territorial de las áreas turísticas de Canarias, con el consiguiente impacto territorial, social, económico y demográfico. El objetivo de este artículo es sistematizar la dimensión territorial de estos procesos residenciales, procediendo al análisis de los factores explicativos y a su modelización territorial.

Palabras clave: áreas turísticas, modelización, oferta de alojamiento extrahotelero, residencialidad, sistematización.

\section{ABSTRACT}

The residential use -permanent or temporary for pleasure- is establishing itself as a basic element of the spatial structure of the tourist areas. The main purpose of this paper is to systematize the different types the residential processes, proceeding to the analysis of the circumstances giving rise to them.

Key words: tourist areas, non-hotel tourism, residential use, systematization.

Fecha de recepción: febrero 2012.

Fecha de aceptación: diciembre 2012.

1 Este trabajo se enmarca en el Proyecto de $\mathrm{I}+\mathrm{D}+\mathrm{i}$ denominado «Evaluación del impacto de las políticas públicas de renovación de destinos turísticos maduros. El caso de las Directrices de Ordenación del Turismo de Canarias» (SolSubC200801000279), financiado por la Agencia Canaria de Investigación, Innovación y Sociedad de la Información del Gobierno de Canarias y el Fondo Europeo de Desarrollo Regional (FEDER). [https://sites. google.com/site/reinventur] 


\section{INTRODUCCIÓN}

Las Islas Canarias (España) constituyen uno de los principales destinos europeos maduros de turismo especializado en el producto «sol y playa». Aunque cada isla y área turística presenta unos rasgos propios, el modelo de oferta de alojamiento turístico se articula en torno al colectivo reglado hotelero. Prueba de ello es que, tomando como referencia los datos de la aplicación Sistema Informático Turístico (Turidata) de la Viceconsejería de Turismo del Gobierno de Canarias, el 48,6\% de las plazas de alojamiento legales del Archipiélago (428.980) de 2011 eran hoteleras. Asimismo, según la Encuesta de Movimientos Turísticos en Fronteras (Frontur) del Instituto de Estudios Turísticos, el 78,8\% de los turistas extranjeros que lo visitaron ese mismo año (10,2 millones, el 18\% del flujo turístico internacional llegado a España) utilizaron ese tipo de alojamiento, siendo el porcentaje más alto de los registrados entre todos los destinos españoles.

Sin embargo, el denominado «tercer boom turístico canario» (1997-2008) ha introducido elementos estructurales que han modificado este modelo de alojamiento turístico, sobre todo, en las áreas turísticas de cuatro de las siete islas del Archipiélago, las consolidadas turísticamente (Tenerife, Gran Canaria, Fuerteventura y Lanzarote). Entre ellos, destacamos los procesos de residencialidad, que, hasta ese momento, se habían concentrado en los núcleos tradicionales de las áreas turísticas -cuando los hubiera-, en sus periferias o en otros municipios (próximos o no).

Estos procesos han sido aún poco estudiados, en cuanto las investigaciones se limitan a un conjunto de trabajos que los han abordado de manera general y tangencial, al incluirlos en estudios relacionados, sobre todo, con el análisis sociodemográfico de la población canaria (Martín, 1984; Díaz, Martín, Pulido y Vera, 1985; Domínguez, 1996; Zapata, 2002; Breuer, 2005a; Domínguez-Mujica, González y Parreño, 2010), siendo escasos los que los han tratado de manera específica y monográfica (Breuer, 2005b; Parreño, 2006; Simancas, Horcajada y García, 2009). Ello contrasta con el importante desarrollo que esta temática ha tenido en la bibliografía especializada y, sobre todo, con el debate teórico y multidisciplinar suscitado en torno a la misma, evidenciado, entre otros, por Cortina, Martínez y Varela (2002) y Huete, Mantecón y Mazón (2008).

Por otra parte, la consolidación progresiva de la residencialidad como un elemento estructural de la dinámica territorial y funcional de las áreas turísticas de Canarias conlleva una cierta contradicción. Ésta se produce porque el actual marco normativo de la política canaria de ordenación territorial del turismo postula la incompatibilidad de los usos residenciales y los turísticos, al concebir a los primeros como un fenómeno negativo, estableciendo no sólo la necesidad de limitarlos, sino trasladarlos hacia otros ámbitos no turísticos.

A pesar de ello, la identificación y clasificación de estos procesos turísticos-residenciales resultan esenciales. Ello se debe, entre otras cuestiones, a que supone un fenómeno con una elevada capacidad de cambio social (Mazón, 2007), demográfico (González Reverté, 2008) y territorial (Vera, 2005), a la vez que, como señalan Huete y Mantecón (2010), afectan a la organización de los mercados de trabajo, la satisfacción de las necesidades educativas y sanitarias o la provisión de servicios públicos básicos (suministro de electricidad y agua, recogida de basuras, etc.). 
Las anteriores cuestiones hacen relevante el análisis de estos procesos de residencialidad. Así, el principal objetivo de este trabajo es realizar una aproximación a su modelización territorial, identificando las circunstancias y razones que los han originado. Se pretende aportar una serie de reflexiones que contribuyan a que estos procesos se incorporen en las complejas operaciones de planificación y gestión territorial de las áreas turísticas, así como en las normas jurídicas que las regula. Para ello, sin perder de vista la definición de estos procesos desde la perspectiva de la demanda -y, por ende, del consumo de la vivienda turísticoresidencial-, también se presta especial atención a la vinculada con la oferta, abordando los procesos de producción de la vivienda turística-residencial y sus efectos sobre la estructura y las tipologías urbanas.

\section{CARACTERIZACIÓN DE LOS PROCESOS DE RESIDENCIALIDAD EN LAS ÁREAS TURÍSTI- CAS DE CANARIAS}

Las expresiones «residencialidad», «residencialización»o «residencialismo»son utilizadas por diferentes investigadores para hacer referencia a un conjunto variado y complejo de procesos que se dan en el marco del sistema turístico y que son de difícil delimitación conceptual y estadística. Ello se debe, entre otras cuestiones, a la propia naturaleza y complejidad de las múltiples modalidades de alojamiento turístico-residencial o de servicios inmobiliarios utilizados, la falta de consenso entre los investigadores para alcanzar un acuerdo respecto al establecimiento de posibles denominaciones, tipologías y criterios de clasificación, así como la escasa y difusa información estadística disponible.

Desde esta perspectiva, cualquier intento de sistematización de este fenómeno debe partir de la premisa de que el principal problema radica en decidir qué es una vivienda turístico-residencial (Huete, Mantecón y Mazón, 2008), en cuanto los límites entre el turismo y la migración residencial no siempre están bien definidos (Huete y Mantecón, 2010). Así, considerando las Recomendaciones Internacionales para las Estadísticas de Turismo (Organización Mundial del Turismo, 2008) y el planteamiento de que las nuevas formas de residencialidad de los alojamientos privados son consecuencia del uso que se les atribuye, los procesos de residencialización que se están produciendo en las áreas turísticas canarias derivan, a riesgo de ser excesivamente simplistas, de dos tipos de usos y pautas de conducta de sus usuarios (figura 1): por una parte, el residencial-turístico o vacacional, y por otra, el residencial (demanda no turística).

\section{El uso residencial turístico-vacacional de los alojamientos turísticos privados}

Se trata de viviendas de «alojamiento privado» que, con diferentes tipos de regímenes de acceso al alojamiento (préstamo, alquiler o en propiedad), son utilizadas por un turista (local, nacional o extranjero), para estancias de diversa duración (cortas, medias o largas), de manera esporádica (ocasional), semipermanente o estacional. Según los datos del Instituto Canario de Estadística, este tipo de alojamiento turístico fue utilizado por el 5,97\% de los 8.576.964 turistas extranjeros llegados a Canarias en 2010.

Aunque esta búsqueda de experiencias de ocio en un espacio-tiempo diferente al de su entorno habitual hace que los usuarios de este tipo de alojamiento se asimilen a los turistas 
Figura 1

CARACTERIZACIÓN DE LOS PROCESOS DE RESIDENCIALIDAD SEGÚN LOS USOS DE LAS VIVIENDAS UBICADAS EN LAS ÁREAS TURISSTICAS

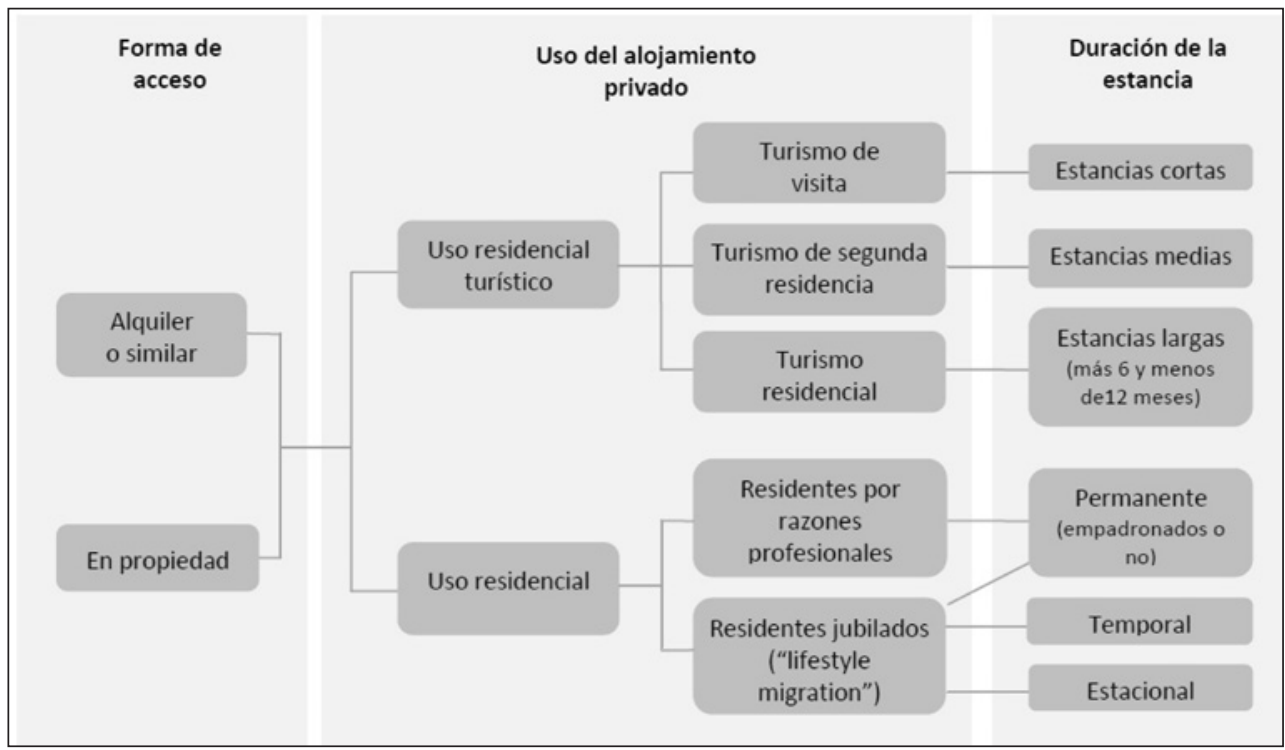

tradicionales (Mantecón, 2008), su orientación residencial-turística hace que tengan unas pautas de comportamiento que les aproximan más al de la población local. Ello explica que presenten una menor inclinación al gasto -más allá de la adquisición y el acondicionamiento de la vivienda- y del número de desplazamientos en la región de referencia, a la vez que una mayor duración de la estancia; a este respecto, resulta de interés las comparaciones entre la oferta reglada y residencial realizada por Exceltur-Deloitte (2005) en relación con su contribución económica y la sostenibilidad de los destinos.

Estos turistas pueden ser clasificados en tres subtipos según el tiempo de la estancia (figura 1):

a) «Turismo de visitas», entendido como aquel que pasa estancias cortas con o en viviendas de familiares y amigos.

b) «Turismo de segunda residencia», en cuanto pasa en una vivienda de su propiedad un mínimo de 15 días a lo largo del año -según Censo de Población y Viviendas de 2001-, los fines de semana y/o de estancias medias superiores al anterior de visitas.

c) «Turismo residencial», en cuanto reside en el destino sin llegar a empadronarse entre 6 y 12 meses consecutivos, pues, a partir de ese momento, el visitante se convierte en residente a efectos estadísticos. Algunos factores que inciden en la decisión de elegir las áreas turísticas como destino residencial son el clima -sobre todo, durante los meses de climatología adversa en su ámbitos geográficos de origen-, el diferencial en el nivel de vida y precios respecto a sus países de origen o las facilidades del transporte aéreo. De esta manera, en algunos casos, este tipo de turistas pasa en estas viviendas más tiempo que en las consideradas como principales en sus países o lugares de origen. 
Del mismo modo, podemos distinguir tres tipos de turismo en función del acceso a estos alojamientos privados vacacionales (figura 1):

a) El turismo de visitas que se aloja con o en viviendas de familiares y amigos. Según Frontur, el 5,9\% de los turistas extranjeros llegados a Canarias en 2011 optó por este tipo de alojamiento.

b) El turismo residencial y de segunda residencia que hace uso de alojamientos de su propiedad. Según Frontur, esta modalidad fue la utilizada por el 8,3\% de los turistas extranjeros llegados a Canarias durante 2011. Esta modalidad suele ser una consecuencia directa de la fidelización del destino turístico, en cuanto resulta decisiva en la decisión de adquirir una vivienda como segunda residencia, dando lugar a una relación entre el lugar y la familia propietaria, que se traduce en un «venir de vacaciones de forma recurrente» (Requejo, 2008).

Dentro de este grupo, se incluye algunas formas de adquisición de casas de vacaciones que han logrado cierta relevancia en los últimos años, como el time-sharing, la multipropiedad o alojamiento en tiempo compartido. Como es sabido, se trata de una fórmula que da derecho de aprovechamiento por turno durante un período determinado de cada año de los bienes inmuebles de uso turístico. Constituye una opción económicamente asumible para el consumidor que no puede invertir en el coste completo de la adquisición de un apartamento o vivienda, al tiempo que constituye para el promotor una forma ideal de obtener un mayor rendimiento por cada inmueble (Capote, 2012).

c) El turismo residencial que arrenda las viviendas. Según el Anuario Económico de España 2012, publicado por el Servicio de Estudios de La Caixa, el 45,5\% de las pernoctaciones que se produjeron en Canarias en 2010 fueron en este tipo de alojamientos.

Estos tres tipos de turismo presentan una problemática diferente desde el punto de vista fiscal y del negocio turístico: mientras los dos primeros no constituyen ningún tipo de actividad económica, al suponer de un «alojamiento no pagado», al tratarse de un servicio prestado por familiares o amigos, gratuitamente o por cuenta propia (casas de vacaciones ocupadas por sus propietarios), el tercero constituye un producto alojativo que, si bien se aproxima conceptualmente al arrendamiento de temporada netamente turístico, forma parte de la oferta no reglada o controlada, en cuanto sus propietarios reciben algún tipo de ingreso al ser alquiladas a terceros, directamente a particulares o a través de agencias de intermediación.

Desde el punto de vista del registro estadístico, estas viviendas no son, en ningún caso, residencias habituales (Instituto Nacional de Estadística, 1994), sino secundarias (Cortina, Martínez y Varela, 2002). Así, constituyen viviendas vacacionales no regladas, de uso temporal (de vacaciones, fines de semana, etc.), que, en su mayoría, ni se identifican con los paquetes turísticos organizados, ni aparecen en la información estadística oficial de la oferta de alojamiento turístico reglado (plazas legales y declaradas). Así, se tratan de plazas turísticas bien «ilegales», en cuanto carecen de todo tipo de licencias y autorizaciones oficiales, bien «no declaradas», en la medida en que sólo aparecen en el mercado -son explotadas-durante algunos períodos del año por parte de su propietario -y no por empresa mercantil- con una finalidad turística y no de arrendamiento urbano, que son comercializadas a través de circuitos no convencionales carentes del control de la administración pública competente. De esta manera, forman parte de las 136.993 plazas ilegales recogidas en el Censo de Establecimientos Turísticos Alojativos y de Equipamiento Complementario elaborado por la Consejería 
de Turismo en 2005, las cuales deben añadirse a las regladas, en la medida en que también conforman la capacidad de alojativa turística total de Canarias, con lo que, según Turidata, ésta ascendería a 565.973 plazas turísticas en 2011. En ambos casos, estas plazas provocan una cierta distorsión del mercado, al carecer de unas garantías mínimas de calidad y servicio, constituyendo, además, una competencia desleal.

\section{El uso residencial no turístico de las viviendas ubicadas en áreas turísticas}

Este segundo tipo de residencialidad implica el uso de viviendas ubicadas en las áreas turísticas que no son ocupadas por turistas, sino por nuevos residentes. De esta manera, su principal rasgo característico es que los procesos y los espacios resultantes carecen de fundamentos turísticos (Obiol y Pitarch, 2011), a excepción del hecho de que se desarrollan en áreas turísticas. Así, comprende a aquellas personas que se trasladan a las áreas turísticas, bien por razones laborales-profesionales, bien por cuestiones estrictamente residenciales de retirados vinculadas con la denominada lifestyle migration (Bell y Ward, 2000; Williams y Hall, 2000), de modo que ahora se comportan como vecinos-propietarios (Huete, 2008), realizando sus visitas o vacaciones en otros lugares. Por tanto, si bien en ambos casos supone un «venir a vivir» (Requejo, 2008), existe una diferenciación en cuanto a su motivación y modos de vida: mientras que el primer caso comprende a personas que se «domicilian» en las áreas turísticas, atraídas fundamentalmente por las expectativas y posibilidades laborales generadas en las mismas -y, por tanto, con la realización de un actividad económica-, el segundo a las que buscan un nuevo estilo de vida (Breuer, 2005b: 372) en un entorno -el turístico- distinto al que han desarrollado su vida profesional y que se convierte en un lugar privilegiado para localizar su residencia permanente, al presentar un clima benigno, un ambiente tranquilo y una buena calidad de vida, y que seguramente conocieron como turistas (estancias cortas), lo cual influyó sobremanera sobre su decisión de elegirlas como su destino residencial, siendo, de nuevo, una de las consecuencias directas de la fidelización del destino.

Esta diferenciación conlleva, a su vez, una dualidad en cuanto al tiempo de estancia (figura 1): mientras las viviendas se convierten para los primeros en su domicilio principal y habitual, arrendado o en propiedad, de modo que no suelen mantener una vivienda principal en sus países de origen, para los segundos constituyen lugares de ocupación permanente o temporal, con carácter puntual o estacional. Asimismo, tomando como referencia las clasificaciones realizadas por Betty y Cahill (1998) y King, Warnes y Williams (2000), podemos distinguir dos tipos de usuarios de este tipo de residencialidad: por un lado, los que usan y disfrutan las viviendas (en propiedad o no), hasta seis meses (visitantes de larga duración) o durante casi todo el año (residentes), y que, por diversas razones, no se inscriben en el padrón; y por otro, los que se vinculan a la correspondiente zona a través de la formalización del empadronamiento, sean o no propietarios de su vivienda, de modo que estos efectivos poblacionales se suman a los que ya lo estaban en los núcleos primigenios -cuando existende las áreas turísticas.

Este último tipo de residencialidad constituye lo que Mantecón (2008) define como «un proceso de reasentamiento de la población en viviendas emplazadas en contextos turísticos». Su cuantificación resulta una labor esencial para su modelización territorial. Sin embargo, la estimación de la oferta de viviendas destinadas a primera residencia y a 
turismo residencial constituye una labor compleja, al tratarse de conceptos con fronteras difusas y de difícil medición a través de las estadísticas convencionales. Asimismo, existe una confusión entre viviendas secundarias y alojamiento turístico extrahotelero (apartamentos, bungalows y villas), evidenciada en un contexto general por Valenzuela (1988). Del mismo modo, en el caso de las viviendas en régimen de propiedad, los datos no permiten diferenciar el uso habitual del secundario, e incluso, dentro del mismo, el de los extranjeros residentes del de los no residentes en España, así como de las desocupadas (Parreño, 2006). Además, se produce un alto grado de subregistro, al que se añade la inexistencia de un registro de los inmuebles de uso secundario alquilados por extranjeros (Parreño, 2006). Por último, existe un desajuste entre la escala administrativa - de la que se suele disponer de datos estadísticos- y la territorial -que hace que las áreas turísticas no coincidan con la anterior-.

La cuantificación de la población residente para los años 2004 y 2009 en las 36 áreas susceptibles de ser calificadas como «turísticas» (tabla 1) se ha realizado mediante la estimación de habitantes por edificación, a través del número de habitantes por sección censal, en cuanto es la unidad estadística de mayor detalle de la que pueden obtenerse datos sobre población: mientras la localización de la edificación se ha hecho a través del Callejero Digital de Canarias y el mapa topográfico 1:5.000 (GRAFCAN, 2004-2009), para la delimitación del suelo dedicado a uso residencial en las áreas turísticas de las islas consolidadas y su evolución reciente se ha recurrido a la elaboración ad hoc de un mapa de ocupación del suelo, tomando como referencia los mapas topográficos 1:1.000 y 1:5.000 de 2009 en formato vectorial y al mapa de ocupación del suelo de Canarias de 2006 elaborado por el Sistema de Ocupación del Suelo de España (SIOSE). Este procedimiento nos ha permitido estimar que el 18,8\% de la población total de Canarias en 2009 residía en los municipios susceptibles de ser calificados como turísticos (16 de los 88 existentes), a la vez que las áreas turísticas concentraban al 10,2\% (216.867 habitantes) de la misma; ambos datos ponen en evidencia la importancia adquirida por este tipo de residencialidad durante el tercer boom turístico. Además, se trata de un fenómeno en expansión; así, utilizando la explotación del Padrón municipal, la tasa de crecimiento poblacional de los municipios turísticos fue de 118,6\% durante el período 19962011, muy superior al conjunto de Canarias $(32,4 \%)$, aunque los municipios no turísticos son los que concentran en términos absolutos la mayor parte de la población (1.708.811 habitantes frente a 393.293 de los municipios turísticos en 2009). Del mismo modo, el 54,3\% de la población de los municipios turísticos reside en sus áreas turísticas, de las que sólo nueve concentran a más de la mitad de su población residente (tabla 1). Todo ello supone un cambio en la tendencia seguida hasta finales de la década de los años noventa, en cuanto las periferias de las principales áreas turísticas eran las que concentraban a la población residente (Zapata, 2002).

La inmigración es el factor que explica la actual estructura de población de las áreas turísticas canarias, en cuanto el $42 \%$ de la población de los municipios turísticos es de origen extranjero (figura 2). Su incidencia adquiere tal envergadura que no sólo influye sobre la estructura de la población más que la propia dinámica natural, sino también les dota de un perfil sociodemográfico particular (González, 2008); ello ratifica el planteamiento de O'Reilly (2007), acerca de que este uso residencial permanente de las áreas turísticas se asemeja más a los procesos migratorios. Desde este punto de vista, si bien el grupo principal 
Tabla 1

DISTRIBUCIÓN DE LA POBLACIÓN RESIDENTE EN LOS MUNICIPIOS TURÍSTICOS DE CANARIAS (2009)

\begin{tabular}{|l|c|c|c|c|c|}
\hline \multirow{2}{*}{\multicolumn{1}{|c|}{ Municipio }} & \multirow{2}{*}{ Isla } & \multicolumn{2}{c|}{$\begin{array}{c}\text { Oferta de alojamiento } \\
\text { turístico }\end{array}$} & $\begin{array}{c}\text { Población residente en las } \\
\text { áreas turísticas ubicadas } \\
\text { en el municipio }\end{array}$ \\
\cline { 3 - 6 } & & $\begin{array}{c}\text { Plazas } \\
\text { turísticas }\end{array}$ & $\begin{array}{c}\text { \% Plazas en } \\
\text { relación total } \\
\text { de Canarias }\end{array}$ & Habitantes & $\begin{array}{c}\text { \% total } \\
\text { municipio }\end{array}$ \\
\hline Mogán & Gran Canaria & 35.716 & 8,4 & 17.825 & 82,2 \\
\hline $\begin{array}{l}\text { San Bartolomé de } \\
\text { Tirajana }\end{array}$ & Gran Canaria & 93.771 & 22 & 39.857 & 76,4 \\
\hline Pájara & Fuerteventura & 31.819 & 7,4 & 14.462 & 69,5 \\
\hline Santiago del Teide & Tenerife & 7.253 & 1,7 & 8.214 & 68,2 \\
\hline Puerto de la Cruz & Tenerife & 23.625 & 5,5 & 21.214 & 65,8 \\
\hline Yaiza & Lanzarote & 15.937 & 3,7 & 8.221 & 59 \\
\hline Tías & Lanzarote & 35.543 & 8,3 & 11.144 & 56,1 \\
\hline Arona & Tenerife & 40.205 & 9,4 & 40.793 & 51,9 \\
\hline Antigüa & Fuerteventura & 14.343 & 3,4 & 5.147 & 49,6 \\
\hline La Oliva & Fuerteventura & 15.748 & 3,7 & 11.262 & 46,5 \\
\hline Guía de Isora & Tenerife & 2.343 & 0,5 & 9.418 & 45,9 \\
\hline Adeje & Tenerife & 47.306 & 11,1 & 19.139 & 44,3 \\
\hline Teguise & Lanzarote & 17.803 & 4,2 & 7.025 & 29,8 \\
\hline $\begin{array}{l}\text { San Miguel de } \\
\text { Abona }\end{array}$ & Tenerife & 4.196 & 1 & 3.078 & 19 \\
\hline
\end{tabular}

Fuentes: Población por sección censal y límites cartográficos de las secciones cenales (Instituto Nacional de Estadística, 2010) / Callejero Digital de Canarias (GRAFCAN, 2010) / Turidata (2009). Elaboración propia.

de los «migrantes retirados» acoge a una amplia variedad de casuísticas (López, Módenes y Yépez, 2007; O’Reilly, 2007), lo habitual es que se conforme por personas de edad avanzada, en su mayor parte, prejubilados, jubilados o retirados de la actividad laboral, de origen europeo, que viven en pareja o en solitario (Zapata, 2002). A su vez, mientras algunos presentan un comportamiento esencialmente turístico (Rodríguez, 2004), otros similar al del fenómeno migratorio (Ferrer, Ribera y Reig, 1997; Williams y Hall, 2000; Casado y Rodríguez, 2002; Raya y Benítez, 2002; Barreto, 2008; Benson y O'Reilly, 2009; Gustafson, 2009; Huete y Mantecón, 2010), hasta el punto que se asimila a lo que Salvà (2005) ha denominado «migración residencial». A este respecto, mientras en el subgrupo de los residentes «permanentes», inscritos o no, pueden observarse rasgos más parecidos a los que se reconocen en los procesos migratorios que en los turísticos, en los subgrupos de «temporales» $\mathrm{y}$ «estacionales» ocurre lo contrario (Huete, Mantecón y Mazón (2008). 
Figura 2

DISTRIBUCIÓN DE LA POBLACIÓN RESIDENTE EN LOS MUNICIOS TURÍSTICOS DE CANARIAS SEGÚN SU ORIGEN

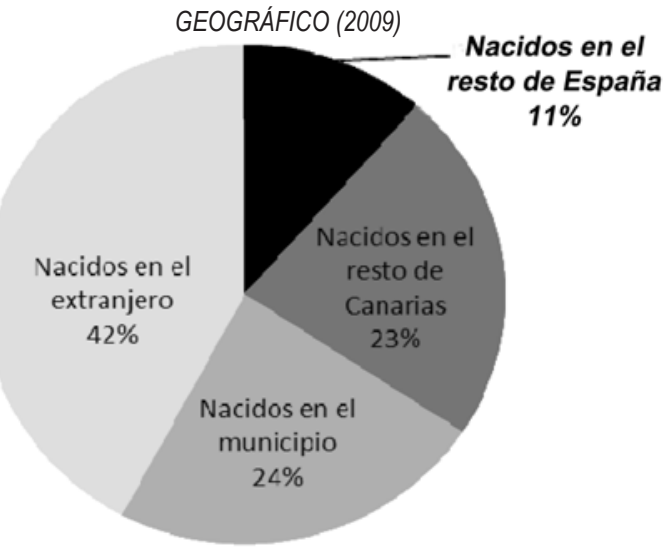

Fuente: Explotación del Padrón Municipal (Instituto Nacional de Estadística). Elaboración propia.

Figura 3

DISTRIBUCIÓN DE LA SUPERFICIE OCUPADA POR LOS USOS TURÍSTICOS Y RESIDENCIALES EN LAS ÁREAS TURÍSTICAS DE CANARIAS (2009)

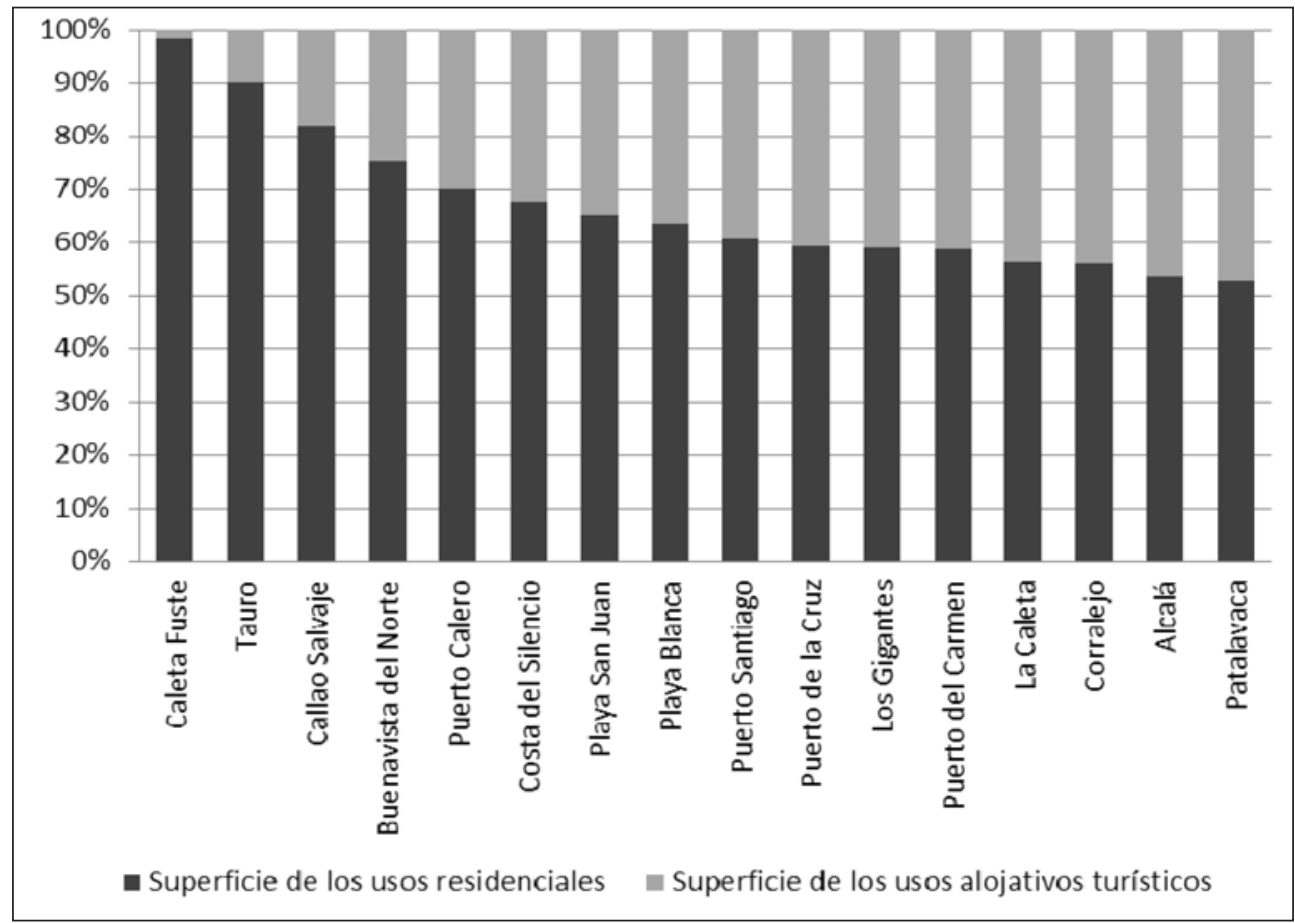

Fuentes: Mapas topográficos 1:1.000 y 1:5.000 (GRAFCAN, 2009) / Mapa de ocupación del suelo (GRAFCAN, 2002) / Callejero Digital de Canarias (GRAFCAN, 2009). Elaboración propia. 


\section{LA MODELIZACIÓN TERRITORIAL DE LOS NUEVOS PROCESOS RESIDENCIALES EN LAS ÁREAS TURÍSTICAS}

La dimensión territorial de ambos procesos de residencialidad ha alcanzado tal envergadura que la superficie ocupada por el uso residencial supera a la de alojamiento turístico en 16 de las 36 áreas turísticas de Canarias (figura 3).

La dimensión territorial de ambos procesos residenciales presentan dos formas concretas: por un lado, la derivada del cambio de usos de las infraestructuras de alojamiento turístico ubicadas en zonas consolidadas; y por otra, la de la asignación del uso residencial como el principal y original de las edificaciones que se localizan en los nuevos desarrollos espaciales (figura 4).

Figura 4

CLASIFICACIÓN DE LA DIMENSIÓN TERRITORIAL DE LOS PROCESOS RESIDENCIALES DE LAS ÁREAS TURISTICAS

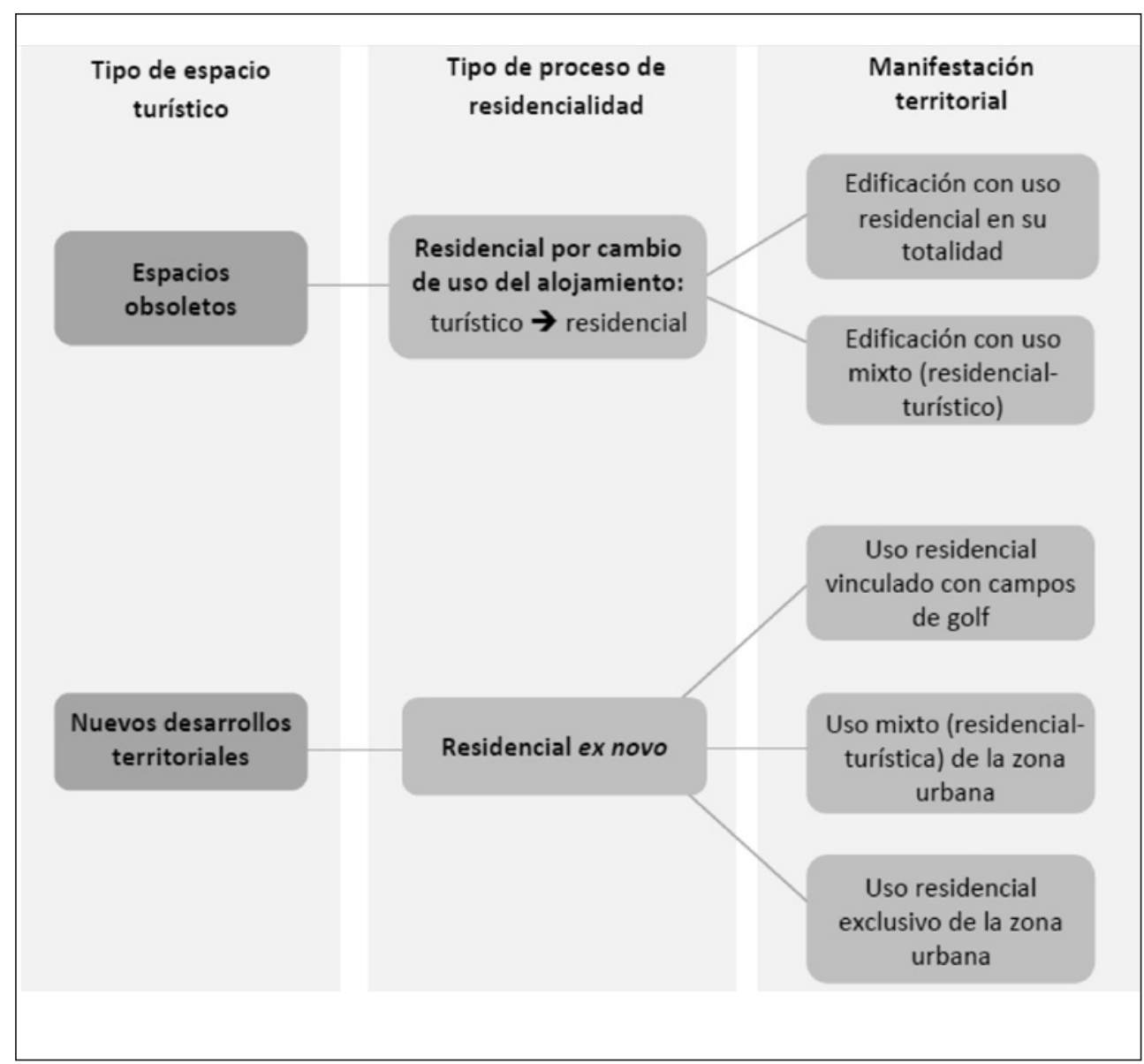




\subsection{La residencialidad por cambio de uso de los alojamientos turísticos en los espacios pre- existentes}

\subsubsection{La aparición del uso residencial y turístico-residencial en los alojamientos turísticos}

Este tipo de uso residencial deriva de la modificación del uso turístico original y vocacional de los establecimientos de alojamiento, sobre todo, extrahotelero, ubicado en las áreas turísticas. Implica su transformación (sustitución) incontrolada en alojamientos que son destinados, bien a viviendas principales (demanda no turística) o habituales (permanentes), bien al turismo residencial o de uso particular (privado) para períodos vacacionales o de ocio («efecto desplazamiento»). Este proceso puede afectar a la totalidad del establecimiento alojativo-vacacional o sólo a algunas de sus unidades, dando lugar a lo que hemos denominado como «uso mixto» (residencial-turístico).

En el primer caso, esta transformación responde a que estos procesos residenciales cubren las necesidades reales de viviendas derivadas del crecimiento de la población residente y que trabaja en el área turística o en su ámbito de influencia; de esta manera, dichas unidades de alojamiento -transformadas ahora en viviendas- se convierten en un bien y un elemento de primera necesidad. A su vez, sus moradores aprovechan las infraestructuras, dotaciones y servicios creados para el desarrollo de actividades vacacionales, lo cual, en ciertas ocasiones, resultan definitivos en la decisión de alquilar o invertir en la compra del inmueble, en cuanto aumentan el atractivo de la zona (Zapata, 2002); de este modo, supone un proceso de residencialización en el que intervienen complicados subprocesos de producción, regulación y consumo (Huete, Mantecón y Mazón, 2008).

Inicialmente la legislación canaria llegó a tolerar, e incluso, facilitar, el uso residencial en los complejos turísticos extrahoteleros. Prueba de ello es la reducción del porcentaje exigido para cumplir con el denominado «Principio de Unidad de Explotación», previsto en el artículo 38 de la Ley 7/1995, de 6 de abril, de Ordenación del Turismo de Canarias; éste exige que cada establecimiento alojativo o conjunto unitario de construcciones, edificio o parte homogénea del mismo se someta a una única titularidad empresarial de la actividad de explotación turística, imponiendo a los propietarios la obligación de efectuar la explotación del conjunto a través de sociedades mercantiles o de un empresario individual, estableciendo como requisitos para acogerse al mismo los de mantener las plazas de alojamiento turístico bajo un único explotador que controle, al menos, la mitad más una de las unidades de cada establecimiento o complejo turístico y disponer del título habilitante por el que los propietarios ceden el derecho de gestión de zonas comunes. Así, se pasó de las dos terceras partes contemplada en la Ley 7/1995 al 51\% en virtud de la Disposición Transitoria Única de la Ley 5/1999, de 15 de marzo, que la modificó, permitiendo, además, que las comunidades de propietarios pudieran desarrollar esas actividades a través de los medios organizativos que juzgasen más oportunos.

Sin embargo, pronto se produjo un cambio de planteamiento. La Ley 2/2000, de 17 de julio, de medidas económicas, en materia de organización administrativa y gestión relativas al personal de la Comunidad Autónoma de Canarias y de establecimiento de normas tributarias, estableció un punto de inflexión; así, planteó la revocación por parte de la Administración pública que gestionaba las aperturas turísticas, es decir, los Cabildos, de las auto- 
rizaciones turísticas previas de aquellos establecimientos alojativos que a fecha de 24 de marzo de 2005 hubieran incumplido dicho Principio. Por su parte, las propias Directrices de Ordenación del Turismo de Canarias (DOT en adelante), aprobadas por la Ley 19/2003, de 14 de abril, plantean la incompatibilidad de los usos residenciales y turísticos, hasta el punto que establecen que «El planeamiento evitará el uso mixto residencial y turístico en las zonas turísticas, por los efectos de deterioro de la oferta alojativa. La regulación del uso residencial dentro de zonas turísticas tendrá entre sus objetivos evitar su posible uso como alojamiento turístico ilegal» (DOT 12); por tanto, no sólo se fija la necesidad de evitar el uso mixto residencial y turístico en las zonas turísticas por los efectos de deterioro de la oferta de alojamiento (DOT 12.1), sino su traslado hacia otros ámbitos no turísticos, con el fin de especializar las zonas turísticas en uno u otro uso. Este planteamiento se continuó con la Ley 6/2009, de medidas urgentes en materia de ordenación territorial para la dinamización sectorial y la ordenación del turismo, en la que se prohíbe tanto la transformación de los hoteles en apartamentos (artículo 14.1), como cualquier cambio hacia la residencialidad. La Ley de Renovación y Modernización Turística de Canarias, aprobada en mayo de 2013, que ha sustituido a la 6/2009, contempla, de nuevo, la necesidad de reconducir la residencialización de los establecimientos turísticos y lograr la especialización del área turística en zonas de uso turístico exclusivo o de uso residencial, a la vez que potencia la reconversión sin límites de determinadas promociones residenciales de viviendas individualizadas y aisladas en la modalidad turística de villas, que, en virtud del Decreto 142/2010, de 4 de octubre, por el que se aprueba el Reglamento de la Actividad Turística de Alojamiento y se modifica el Decreto 10/2001, de 22 de enero, por el que se regulan los estándares turísticos, suponen una modalidad de alojamiento extrahotelero; aunque posibilita el mantenimiento de los suelos mixtos, fijando, vía desarrollo reglamentario, las condiciones de compatibilidad entre ambos usos, plantea su especialización hacia el uso turístico y residencial.

Este último objetivo supone una cierta ruptura con el planteamiento del urbanismo tradicional que, en su generalidad, concibe a los usos turísticos alojativos como una variante de los residenciales. En este sentido, estimamos que se trata de una decisión excesivamente rigurosa, no exenta de complicaciones, sobre todo, en relación con cuatro cuestiones. La primera se refiere que, compartiendo lo planteado al respecto en el Dictamen 11/2002 del Consejo Económico y Social de Canarias sobre las Directrices de Ordenación General y del Turismo de Canarias, esta medida nos parece injusta socialmente, no sólo por la preeminencia a los intereses económicos de las empresas que se dedican a la explotación turística sobre otros intereses sociales y económicos, sino porque también se trata de una cuestión compleja de difícil solución en situaciones consolidadas. Por otro lado, en la medida en que estos procesos residenciales solucionan, como se ha indicado, las necesidades reales de viviendas en las áreas turísticas o en sus ámbitos de influencia, el cambio de uso alivia el excesivo consumo del territorio, a la vez que supone un uso alternativo a aquellas unidades de alojamiento que quedan fuera de mercado. En tercer lugar, se trata de un proceso de cambio de uso que no es consecuencia de una decisión planificada, sino, por el contrario, de una dinámica natural de los propios desarrollos turísticos y, en concreto, de la concurrencia de las condiciones de oportunidad o demanda de los mercados turísticos o inmobiliarios. Por último, contradice, en cierta medida, lo establecido en la Directriz de Ordenación General 70, que plantea que "el planeamiento urbanístico evitará, en los sectores con destino residencial, la zonificación 
funcional y procurará la implantación de modelos urbanos que propicien el incremento de la complejidad e integración social y la mezcla de usos compatibles dentro del tejido urbano"; en este sentido, se trata de una estrategia de zonificación dirigida a la especialización, segregación y, en cierta medida, resortización y artificialización de los espacios turísticos.

No obstante, la existencia de este modelo de residencialidad en los establecimientos extrahoteleros de las áreas turísticas de Canarias conlleva una serie de problemas.

En primer lugar, se incumple el citado Principio de Unidad de Explotación, en cuanto plantea serios problemas en un buen número de edificios de apartamentos en régimen de comunidad de propietarios, adquiridos antes de la entrada en vigor de la Ley de 7/1995, en concreto, en 106 (el 6,1\%) de los 1.738 establecimientos extrahoteleros identificados en el Censo de Establecimientos Alojativos y Equipamientos Complementarios, elaborado en 2005 por la entonces Consejería de Turismo del Gobierno de Canarias. Este incumplimiento se debe a que la introducción del uso residencial en estos establecimientos provoca que las unidades de alojamiento turístico no lleguen al 50\%, con lo que las empresas explotadoras no alcanzan los mínimos establecidos en la Ley 5/1999; a este respecto, el entonces consejero del Turismo del Gobierno de Canarias reconoció en una respuesta parlamentaria (Boletín Oficial del Parlamento de Canarias, núm. 163, de 2 de junio de 2006) que, entre los años 2000 y 2004, se iniciaron 81 expedientes sancionadores por incumplimientos del Principio y que fueron resueltos con sanción de multa por un importe total de 711.079,19 euros. En cualquier caso, el control de la residencialidad en este tipo de establecimientos que originariamente tuvieron una vocación turística pasa por impedir el otorgamiento de escrituras de división horizontal en los edificios destinados a la explotación turística, con la excepción de los denominados «bungalows», que legalmente no están sometidos a la Ley 40/1960, de Propiedad Horizontal.

El segundo problema deriva de la práctica habitual de que las unidades de alojamiento turístico objeto ahora del uso residencial no se dan de baja como tales, a pesar de que se comercializan en un régimen diferente al mismo. Tampoco se acogen a la Ley 29/1994, de 24 de noviembre, de arrendamientos urbanos, cuando satisfacen la necesidad permanente de vivienda del arrendatario (artículo 2.1) en un habitual régimen de alquiler, con lo que se inserta en la esfera del fraude fiscal y la economía sumergida por parte de sus explotadores y propietarios.

El tercer problema se refiere a la frecuente proliferación de pequeñas obras de reforma en el exterior de las viviendas (alojamientos), al margen de cualquier criterio de homogeneización física y estética, e incluso, de la preceptiva licencia municipal, con el consiguiente deterioro del aspecto estético y estructural del complejo. Además, el afán rentista de los propietarios ha llevado, en algunos casos, a ofrecer infraviviendas a rentas muy bajas. Del mismo modo, la sustitución del uso turístico preexistente no se acompaña de actuaciones de esponjamiento urbanístico, con el fin de incrementar las zonas verdes, los espacios públicos y los equipamientos colectivos.

El cuarto problema se produce cuando se mantiene el uso turístico, dando lugar a un uso mixto del establecimiento alojativo. Así, resulta habitual que se produzca una competencia entre las plazas no regladas -o al menos, como ya se ha comentado, con una utilización turística irregular, fuera del control- destinadas al uso residencial y las correspondientes a la oferta de alojamiento reglada. 
Por último, pueden aparecer incompatibilidades entre los usos turísticos y residenciales, con los conflictos de diverso índole indicados por Exceltur (2005). Ello se debe, sobre todo, a los diferentes hábitos, horarios, actividades, actitudes y necesidades de los residentes y de los turistas, pues, como se indica en la Memoria del Plan Insular de Ordenación de Tenerife (2002), «el espacio turístico es un objeto de consumo vacacional que se percibe y se vive de forma diversa al espacio residencial».

\subsubsection{Razones del cambio de uso del turístico al residencial de los establecimientos alojativos}

Aunque este modelo de residencialidad puede surgir debido a que el correspondiente instrumento de planeamiento urbanístico aprobado antes de la promulgación de la Ley 19/2003 permitía indistintamente los usos turísticos y residenciales en una zona, lo más habitual es que aparezca como consecuencia de una transformación del uso turístico al residencial. Este afecta fundamentalmente a los alojamientos extrahoteleros, pues, aunque los hoteleros pueden optar por su cierre, lo más frecuente es que sean objeto de un cambio de titular -con el fin de lograr una liquidez inmediata-, de una especialización en categoría de la cadena o de la concentración en actividades principales por parte de inversores que entraron en el sector en busca de diversificación.

Quizás el factor decisivo que más ha contribuido a este cambio de uso es su obsolescencia (física, funcional, de modelo de negocio, de modelo organizativo, etc.). Ésta no surge necesariamente por un mal funcionamiento de su gestión, sino porque su utilidad se vuelve insuficiente o es superada por una tendencia (moda) que, de alguna manera, lo convierte en old-fashion («fuera de moda») (Simancas, 2012). Esta situación suele originarse por la falta de operaciones de renovación de los alojamientos turísticos que trasciendan las actuaciones de rehabilitación edificatoria, que comprenden la obra menor o de estricto mantenimiento (conservación), como consecuencia de un proceso de deterioro continuo de los márgenes empresariales y una cierta descapitalización, en cuanto las inversiones en las mismas suelen depender de los márgenes de beneficios, de modo que sólo se abordan bajo condiciones en las que puedan recuperarse vía precio de contratación (González, León y Padrón, 2006). Ello acentúa el deterioro y desfase de los alojamientos turísticos, que, a su vez, tiende a agravarse a medio y largo plazo al disminuir tanto la rentabilidad como la diversidad y la calidad de los servicios. Este proceso provoca, a su vez, una pérdida de cuota de mercado, con el consiguiente impacto sobre los principales indicadores del negocio turístico (número de pernoctaciones, estancia media, gasto, índices de ocupación, etc.). Ésta suele contrarrestarse con la aplicación de una política agresiva de descuentos, que genera un círculo vicioso de precios ajustados, con la consiguiente modificación de los segmentos y patrones de demanda hacia menor calidad-diferenciación, y menor precio. Si bien ello posibilita unos niveles mínimos de ocupación que garantizan una rentabilidad que, al menos, cubren los costes de explotación y, en el mejor de los casos, de mantenimiento y ornato, no sucede lo mismo con los márgenes de beneficios, que siguen reduciéndose, con la consiguiente repercusión sobre la disponibilidad de fondos económicos susceptibles de ser destinados a la modernización, mejora y cualificación parcial y/o total de las instalaciones, equipos y servicios turísticos. Ello provoca un descenso continuado del valor de tales activos hasta alcanzar unos precios relativamente bajos y asequibles, que resulta decisivo para que determinados segmentos de población con 
un bajo poder adquisitivo puedan optar por la compra o alquiler de las hasta entonces unidades de alojamiento del complejo extrahotelero. Todo ello repercute en una reducción de la rentabilidad privada y social del negocio turístico, con la consiguiente salida del mercado turístico, que, a su vez, explica el cambio de uso de los inmuebles turísticos a residenciales, así como una elevada rotación de la propiedad, sobre todo, cuando no se cumplen las expectativas de amortización y generación de beneficios. Este proceso explica que, según Turidata, 20.201 plazas extrahoteleras $(-8,4 \%)$ salieron del mercado entre 2000 y 2011.

Otro factor explicativo es la incidencia de la denominada «moratoria turística canaria»y, en concreto, el objetivo de cualificar y especializar, vía modalidad y categoría, el alojamiento turístico. Como es sabido, se trata de una política pública de regulación del mercado a través del establecimiento de límites, ritmos y tipos de crecimiento de la oferta de alojamiento turístico, que, iniciada con la promulgación del Decreto 4/2001, por el que se acordó la formulación de las Directrices de Ordenación General y las del Turismo, continuó con la Ley 19/2003, por la que éstas se aprobaron, y se ha prolongada hasta la actualidad en virtud de la Ley 6/2009, de 6 de mayo, de medidas urgentes en materia de ordenación territorial para la dinamización sectorial y la ordenación del turismo, que ha modificado parcialmente a la anterior. Así, desde la primera de estas normas se ha excluido la posibilidad de otorgar nuevas autorizaciones turísticas previas para oferta de alojamiento extrahotelero; en virtud del artículo 24 de la Ley 7/1995, ésta supone el elemento administrativo que autoriza el uso del territorio en relación con el proyecto técnico presentado, a la vez que fija la fecha de inicio de su eficacia, y, por tanto, de la edificación. De esta manera, la continuidad en el mercado turístico de este tipo de oferta de alojamiento ha quedado limitada exclusivamente a las operaciones de renovación edificatoria, cuya incentivación pública ha presentado más oscuros que claros (Simancas, 2012).

La atomización y dispersión de la propiedad de las unidades de alojamiento turístico constituye otro factor que ha contribuido a esa deriva hacia el uso residencial de los alojamientos turísticos extrahoteleros, a la vez que éstos sean los que lo padezcan de forma mayoritaria. Si bien su explotación se produce de manera coordinada y concentrada en una única titularidad empresarial bajo el mencionado Principio de Unidad de Explotación, el cual intenta evitar que una multitud de agentes comercialice un mismo complejo, dicha fragmentación de la propiedad hace que sus múltiples titulares no sólo se comporten de manera similar a «microcapitalistas» (Santana, 2005), que siguen la generalizada racionalidad empresarial empeñada en la máxima rentabilidad a corto plazo, sino que también supone una suma de distintas decisiones e intereses, en su mayoría, contrapuestas e individuales. Esta situación contrasta con el comportamiento de los alojamientos hoteleros, donde se produce una concentración de la propiedad en un único o en un reducido número de propietarios, que, en la mayoría de las ocasiones, no han asumido su explotación (separación entre propiedad y gestión), relegándola a las grandes cadenas hoteleras o holdings a través de fórmulas de franquicia, contratos de arrendamiento, de explotación o similares.

En cualquier caso, este cambio de uso responde a la pretensión última de los propietarios de estos alojamientos turísticos extrahoteleros -ya amortizados- de continuar con la obtención de ingresos; en este sentido, recuérdese que éstos han constituido una forma de ahorro local familiar o de inversión de profesionales, que, ante la expectativa de autofinanciación y de convertirse en una fuente complementaria de recursos -además de un lugar para disfrutar 
las vacaciones estivales-, adquirieron uno o varios apartamentos o bungalows mediante el sistema de venta anticipada (sobre planos y con abono previo de parte del precio total). El resultado es que estos propietarios pasan de ser inversores-rentistas vinculados con la actividad turística -y, por ende, dependientes de operadores turísticos- a arrendadores de bienes inmuebles urbanos.

\subsection{La asignación de la residencialidad como el uso primigenio y principal de las nuevas edi- ficaciones y espacios turísticos}

\subsubsection{Tipos de procesos de residencialidad en los nuevos espacios turísticos}

Esta modalidad de residencialidad ex novo surge como consecuencia de la asignación de la función residencial (permanente o turística) como el uso principal y original de las edificaciones y urbanizaciones construidas en los nuevos espacios turísticos que han surgido de forma acelerada en zonas aisladas, próximas o anexas a las áreas turísticas preexistentes. Su aparición ha convertido a los centros vacacionales en ámbitos residenciales o, en el mejor de los casos, mixtos. Así, podemos distinguir tres tipos de modelos de residencialidad (figura 4).

El primero se produce en urbanizaciones tipo ciudad-jardín, de baja densidad y cierto desarrollo superficial, con viviendas unifamiliares aisladas de lujo o alto standing, que se ubican en torno o en el área de influencia de un campo de golf; hay que señalar que la política pública canaria ha concebido a este tipo de oferta complementaria de ocio de gran prestigio social como un elemento estructural de la estrategia de cualificación del modelo turístico derivado del tercer boom turístico. Esta vinculación «residencialidad-campos de golf» explica que 12 de los 25 campos de golf existentes en Canarias se construyesen entre 2000 y 2009, siendo, además, la forma de ocupación del suelo turístico que más ha aumentado durante el mismo, con una tasa de crecimiento del 116,8\% (Simancas, García, Dorta y Falero, 2011).

De este modo, aunque la construcción de los campos de golf se ha vinculado formalmente con una estrategia local de atraer un «turismo de calidad», también se ha relacionado con los procesos de residencialidad. Así, mientras que diez campos de golf están vinculados a urbanizaciones turísticas y residenciales, cuatro se relacionan exclusivamente con este tipo de uso (figura 5). Así, podemos diferenciar tres subtipos de situaciones (Villar, 2011) en las que las urbanizaciones residenciales se insertan en las estructuras que Feo (2001) denomina como los «espacios de golf»:

a) Las zonas residenciales se asocian directamente al campo de golf, en cuanto forman parte del mismo proyecto, siendo planificado como un mismo conjunto.

b) El campo de golf se proyectó y construyó sin usos residenciales, pero que, con posterioridad, fueron colmatándose de viviendas que han aprovechado su cercanía física o visual.

c) La urbanización residencial se proyecta como parte de campo de golf, induciendo, con posterioridad, el desarrollo de una segunda orla de viviendas en la periferia de la anterior, por parte de promotores ajenos al primigenio que intentan beneficiarse de las sinergias del mismo.

De esta manera, los campos de golf se han convertido en factores de atracción del residencialismo (Feo, 2001), con la consiguiente instrumentación inmobiliaria (Vera y Baños, 


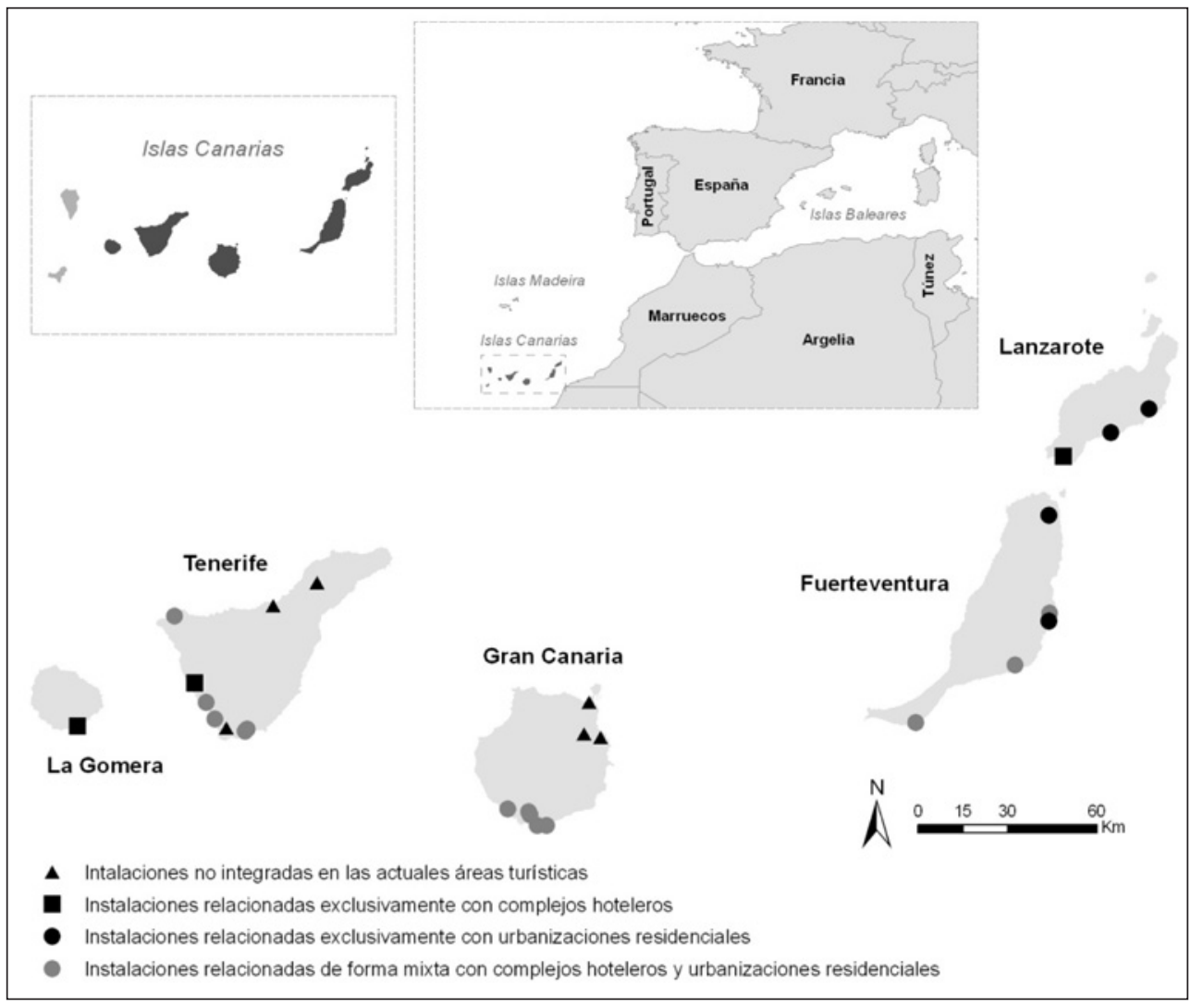

Fuentes: Diva-Gis Free Data / GRAFCAN. Elaboración propia.

2010). Con ello se aprovecha la venta de «los espacios de calidad» generada por este tipo de oferta recreativa (figura 6), generándose un rentable binomio. Éste se sustenta en que, como señala Villar (2011), al margen de que el comprador sea usuario o no de este tipo de instalación, el uso residencial se beneficia de cinco fortalezas inherentes a los mismos: a) la propia posibilidad de practicar este deporte; b) el paisaje (los valores del campo como fondo escénico de la vivienda, el carácter de exclusividad y aislamiento, el clima local, etc.); c) la amenidad y la calidad ambiental (las valores como áreas con vegetación, espacios libres de edificación, etc.); d) la privacidad del campo, que, además, sirve para vender lo diferenciado, el sosiego y el alejamiento de las grandes concentraciones turísticas-urbanas; y e) la posibilidad de jugar en otoño e invierno, épocas en las que los jugadores europeos no pueden hacerlo, debido a la climatología de sus países o lugares de origen. Asimismo, la simple presencia de un campo de golf añade valor a los inmuebles próximos, revalorizando el suelo circundante e impulsando fuertes expectativas de urbanización a través de operaciones de 


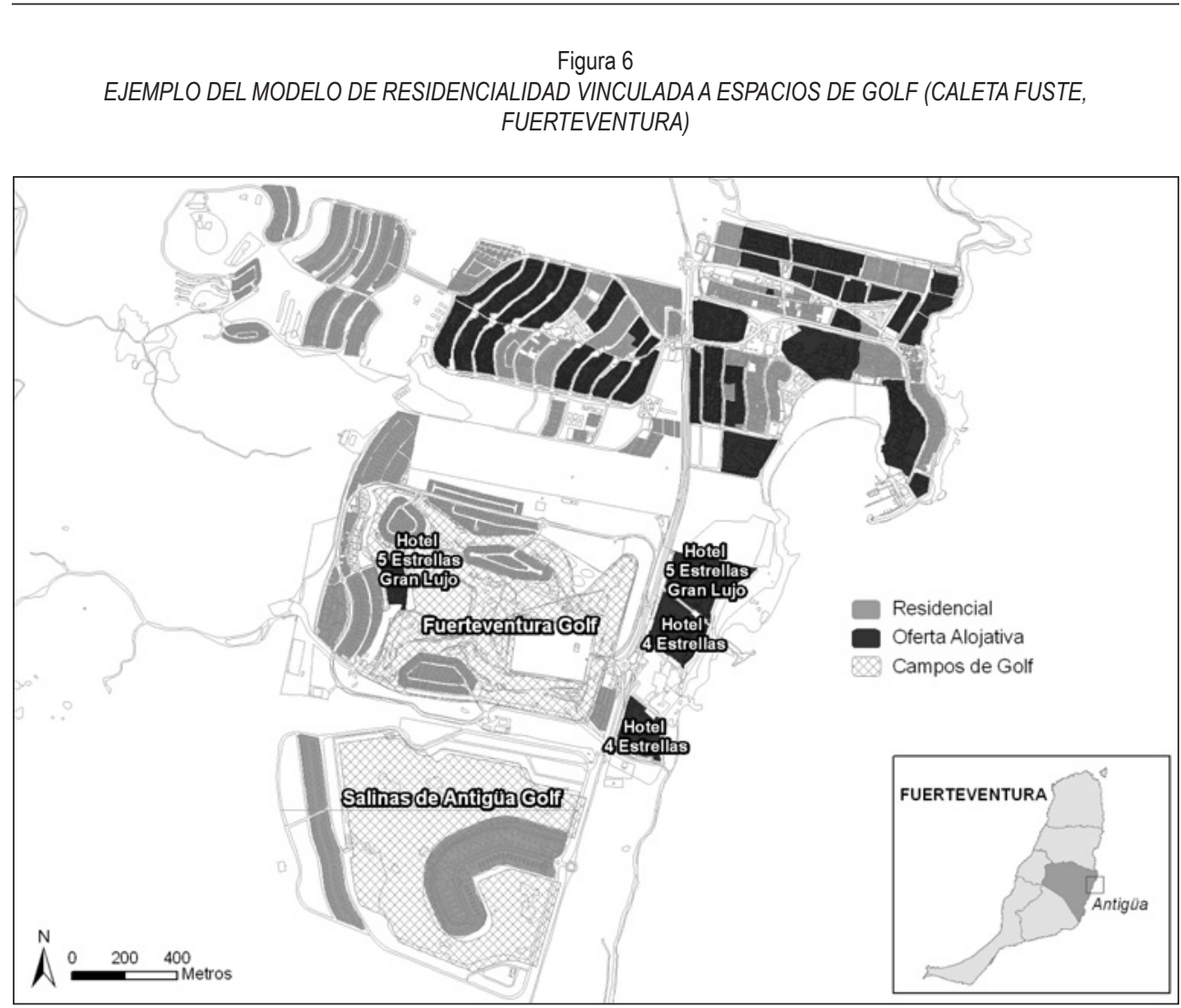

Fuentes: Mapas topográficos 1:1.000 y 1:5.000 (GRAFCAN, 2009). Mapa de ocupación del suelo (GRAFCAN, 2002). Callejero Digital de Canarias (GRAFCAN, 2009). Elaboración propia.

marcado sesgo especulativo; así, según datos de Aymerich Golf Management (2009) citado por Villar (2011), el precio de venta de las viviendas y parcelas cercanas a los campos de golf puede ser del $50 \%$ y del $100 \%$ respectivamente, dependiendo de si se encuentran más o menos cercanas a la primera línea de campo.

El segundo modelo corresponde con aquel en el que la residencialidad constituye un elemento estructural de los nuevos desarrollos territoriales del turismo (figura 7). Así, los complejos residenciales de nueva creación y alto standing se mezclan con alojamientos turísticos, generalmente los que hemos denominado como «resort hoteleros horizontales». El resultado es una estructura territorial que responde, por un lado, a la actual dinámica de la doctrina urbanística general de aplicar un criterio de mezcla de usos y, en este caso, de combinar los dos modos de utilización del espacio turístico - esto es, la residencia permanente y el alojamiento temporal (de corta, media y larga estancia) por razones de ocio-, y por otro, a la estrategia de sustituir los establecimientos convencionales de apartamentos por viviendas «de lujo» destinadas a primera y segunda residencia. Con ello, no se dan las exclusividades y exclusiones propias de la zonificación convencional, tratando de evitar la segregación fun- 


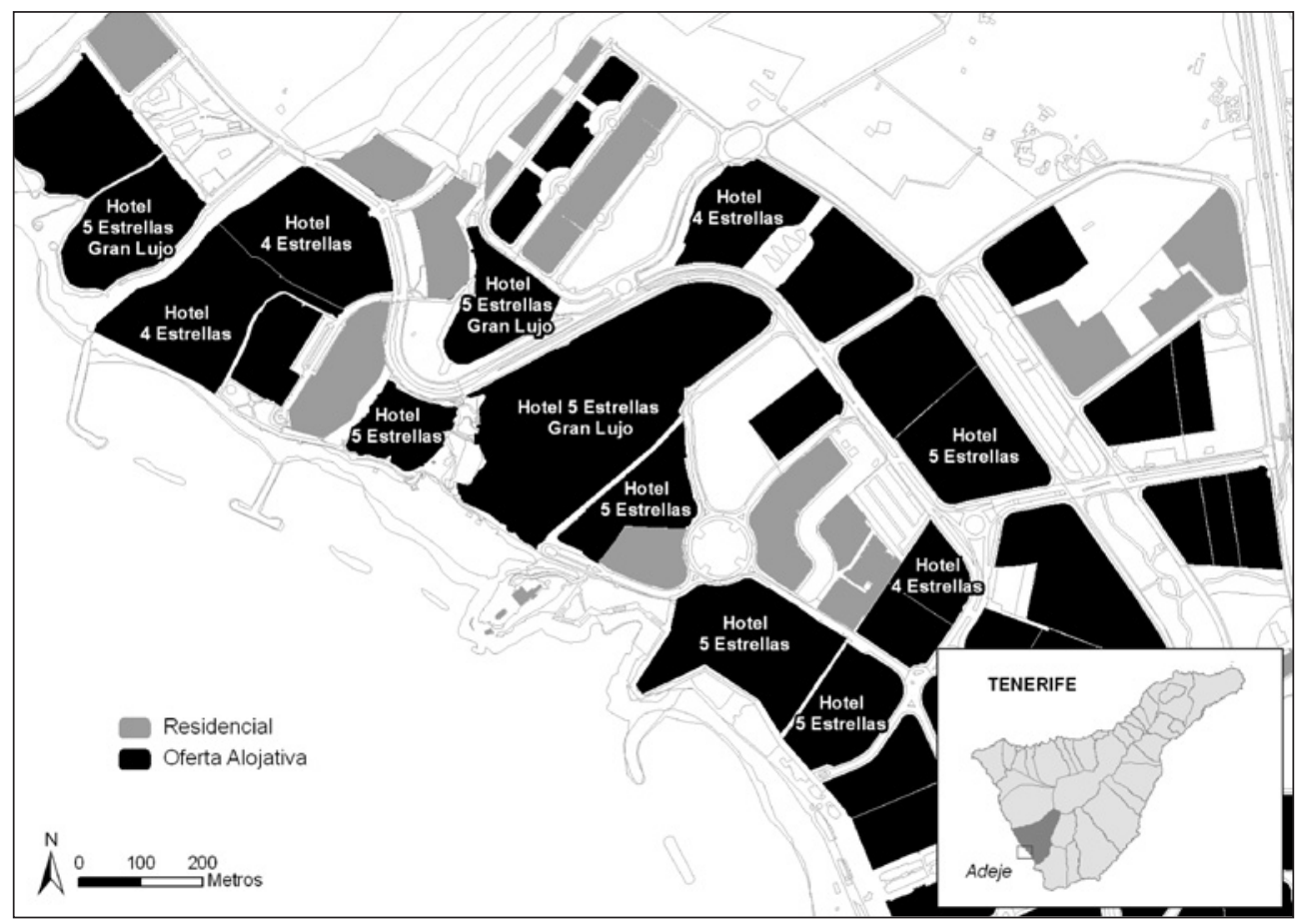

Fuentes: Mapas topográficos 1:1.000 y 1:5.000 (GRAFCAN, 2009). Mapa de ocupación del suelo (GRAFCAN, 2002). Callejero Digital de Canarias (GRAFCAN, 2009). Turidata (2009). Elaboración propia.

cional de las actividades en el espacio turístico; por el contrario, se genera un mix territorial, en el que el turismo residencial no compite con el «turismo hotelero», produciéndose una relación de complementariedad, simbiosis, e incluso, sinergia -reforzamiento- o, cuando menos, de neutralidad, compatibilidad o coexistencia.

La tercera forma de residencialidad resulta de la materialización territorial de las expectativas generadas por el mercado inmobiliario. Aunque un porcentaje de las mismas responden directamente a una demanda real por parte de la población residente, otro se relaciona con el proceso de desarrollo inmobiliario de urbanizaciones en segunda línea como sustituto del desarrollo turístico (Vera, 2005) y, por tanto, a la intensa vinculación entre lo turístico y lo inmobiliario puesta de manifiesto, entre otros, por Requero (2008), o mejor dicho, a la prevalencia de la actividad de la construcción y la acumulación de capitales sobre el «negocio» turístico. Ello ha dado lugar a una doble casuística: por un lado, aquellas edificaciones residenciales de nueva construcción y que forman parte de los planes urbanísticos aprobados y materializados durante el tercer boom turístico canario (figura 8); y por otro, aquellas que derivan de la decisión de buena parte de los promotores que disponían de licencias de 


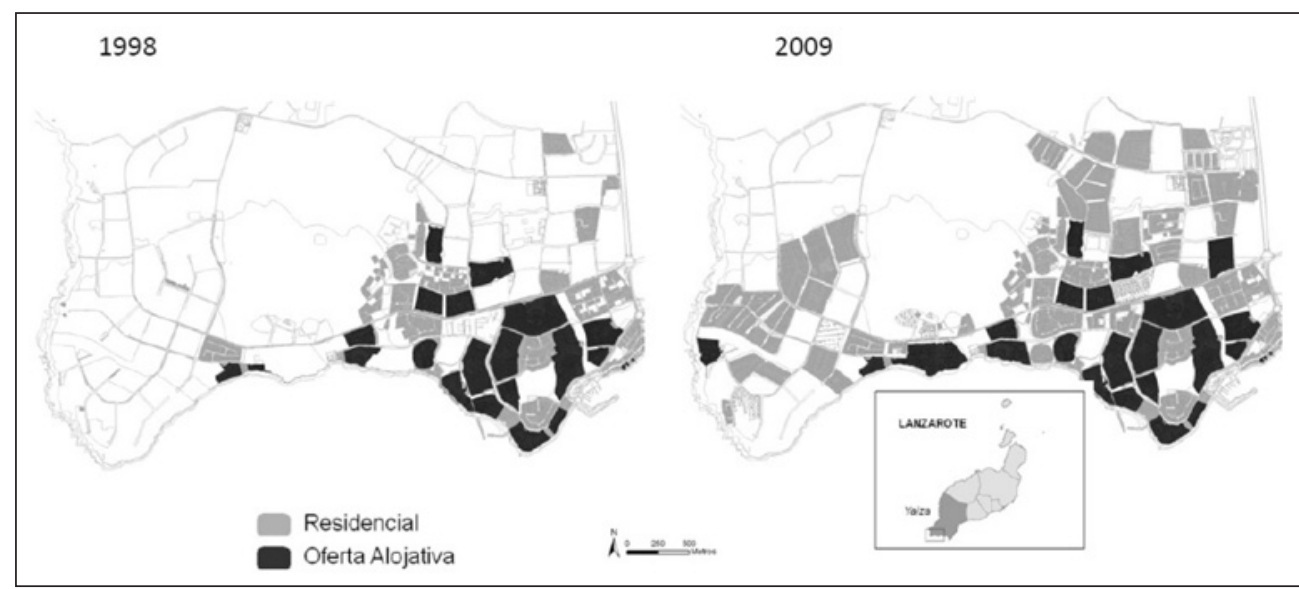

Fuentes: Mapas topográficos 1:1.000 y 1:5.000 (GRAFCAN, 2009). Mapa de ocupación del suelo (GRAFCAN, 2002). Callejero Digital de Canarias (GRAFCAN, 2009). Turidata (2009). Elaboración propia.

obras para la construcción de complejos extrahoteleros, de transformarlas en residenciales, amparándose en las excepciones contempladas en el artículo 4.2.b de la Ley 6/2001, de Medidas Urgentes en materia de Ordenación del Territorio y del Turismo de Canarias, con la consiguiente recuperación de un conjunto de proyectos urbanísticos truncados en los años setenta y ochenta por diversas razones y que se encontraban paralizados. El resultado ha sido la sustitución de los grandes bloques de apartamentos por viviendas unifamiliares adosadas o aisladas. Además, en la mayoría de los casos, los ámbitos territoriales resultantes de este último modelo de residencialidad ex novo carecen de un verdadero fundamento turístico, al tener su capacidad productiva asociada a la residencial, sin apenas componentes de ocio, con un atractivo, comportamiento y componentes que se asimilan a un sucedáneos del producto turístico; a su vez, se ha favorecido la clasificación de una gran cantidad de suelo turístico, generando un modelo insolidario y depredador de recursos (Vera, Palomeque, Marchena y Antón, 2011), así como una urbanización, por lo habitual, carente de los mínimos niveles de la sostenibilidad urbana.

A diferencia de las dos primeras formas de residencialidad ex novo, que suponen desarrollos urbanísticos que, en su mayoría, comparten la especificidad de la urbanización turística, en cuanto constituyen espacios con una atenuada movilidad trabajo-residencia a favor del binomio ocio-residencia, con la pérdida de significado de equipamientos de la vida urbana convencional (docentes, culturales) a favor de otros deportivos y/o recreativos (Antón, 1998), el uso residencial es prácticamente hegemónico de las urbanizaciones resultantes de este último modelo. El fin último ha sido alcanzar el máximo beneficio empresarial en el mínimo tiempo posible, con la consiguiente secuela de mediaciones y distorsiones especulativas. De esta manera, éste se aproxima a lo que Mazón (2002) ha denominado como «turismo inmobiliario», al derivar esencialmente del proceso de construcción y venta de urbaniza- 
ciones, sustentado en un planeamiento urbanístico que no sólo ha enfatizado la dimensión especulativa del fenómeno urbanístico-inmobiliario, sino también la producción masiva de viviendas primarias y secundarias en entornos con un potencial atractivo turístico (Vera y Marchena, 1996; Gustafson, 2009). Por tanto, este tipo de residencialidad se relaciona con la «pujante hibridación entre lo turístico y lo inmobiliario que bajo el rótulo de 'turismo residencial' presenta como especificidad su doble condición de producto turístico e inmobiliario» (Valenzuela, 2006: 268). Ello explica la maximización del volumen de producción (los alojamientos residenciales) a través de un «urbanismo por proyectos», que sigue un modelo de planificación «en mancha de aceite», que suele dar lugar a piezas aisladas e inconexas entre sí, sin visión de conjunto del espacio turístico -entre las áreas turísticas y dentro de las mismas-.

Este modelo de residencialidad ex novo ocupa el 12,6\% (1.464,2 hectáreas) de la superficie total de las áreas turísticas, de la cual un $40,4 \%$ se ha construido con posterioridad a 1998. Además, supera a la superficie ocupada por los alojamientos turísticos en 17 de las 36 áreas turísticas (tabla 2). Este importante desarrollo se debe al extraordinario crecimiento de su extensión superficial, del 67,7\% con respecto a la construida hasta 1998. Éste ha hecho que este tipo de zonas residenciales sea la segunda forma de producción de espacio turístico durante el tercer ciclo turístico expansivo, ligeramente por detrás de la construcción de los campos de golf y por delante de la oferta de alojamiento horizontal (Simancas, García, Dorta y Falero, 2011). Con ello, la residencialidad ex novo distorsiona la pretensión de la DOT 66, de que «el planeamiento minimizará el consumo de suelo y dará prioridad al uso eficiente del suelo ya ocupado, mediante su renovación y reutilización».

\subsubsection{Razones que justifican la aparición de la residencialidad como el uso vocacional de los nuevos espacios turísticos}

Este tipo de uso residencial ex novo surge de la convergencia de un conjunto de factores, entre los que destacamos los siguientes.

En primer lugar, la propia dinámica del mercado turístico. La construcción de viviendas residenciales supone una reacción adaptativa al cambio de tendencia en la oferta de alojamiento turístico que se produjo a partir de mediados de la década de los noventa. Así, se ha optado por la cualificación (excelencia) y especialización, vía modalidad (hotelera) y categoría (igual o superior a las cuatro estrellas), del modelo de oferta de alojamiento turístico, en coherencia con el planteamiento de que una mayor calidad garantiza mayores precios.

En segundo lugar, como ya se ha comentado, el uso residencial se ha revelado como un mecanismo eficaz y sustitutivo de otorgamiento de licencias urbanísticas para eludir la prohibición de construir nuevos alojamientos extrahoteleros derivada de la moratoria turística. Así, numerosos promotores no sólo han logrado materializar sus proyectos turísticos durante el tercer boom turístico a través de su transformación interesada en residenciales, sino que también han reactivado una serie de planes parciales aprobados con anterioridad al mismo.

Esta transformación también se ha visto favorecida por una actitud receptiva por parte de los ayuntamientos, sobre todo, por parte de aquellos gobiernos locales que buscan contar a corto plazo con la suficiente capacidad económica para hacer frente a la creciente demanda de servicios públicos locales. Esta situación no sólo es deudora, en gran medida, de la Ley 
Tabla 2

DISTRIBUCIÓN DEL CRECIMIENTO DE LA SUPERFICIE OCUPADA POR EL USO RESIDENCIAL Y LA OFERTA DE ALOJAMIENTO EN LAS ÁREAS TURISTICAS DE CANARIAS (1998-2009)

\begin{tabular}{|c|c|c|c|c|c|c|c|c|}
\hline \multirow[t]{2}{*}{ Área turística } & \multirow[t]{2}{*}{ Isla } & \multirow{2}{*}{$\begin{array}{c}\text { Superficie } \\
\text { edificada } \\
\text { entre 1998- } \\
2009 \text { (en } \\
\text { hectáreas) }\end{array}$} & \multicolumn{2}{|c|}{$\begin{array}{c}\text { Superficie } \\
\text { ocupada por el } \\
\text { uso residencial }\end{array}$} & \multicolumn{2}{|c|}{$\begin{array}{c}\text { Superficie } \\
\text { ocupada por } \\
\text { la oferta de } \\
\text { alojamiento }\end{array}$} & \multicolumn{2}{|c|}{$\begin{array}{c}\text { Superficie ocupada } \\
\text { por otros usos* }\end{array}$} \\
\hline & & & $\begin{array}{c}\text { En } \\
\text { hectáreas }\end{array}$ & $\%$ & $\begin{array}{c}\text { En } \\
\text { hectáreas }\end{array}$ & $\%$ & En hectáreas & $\%$ \\
\hline Playa Blanca & Lanzarote & 396 & 192,9 & 48,7 & 59,4 & 15 & 143,7 & 36,3 \\
\hline Caleta Fuste & Fuerteventura & 357,8 & 75,3 & 21 & 25,1 & 7 & 257,5 & 72 \\
\hline Corralejo & Fuerteventura & 277,7 & 79,3 & 28,6 & 28,3 & 10,2 & 170,2 & 61,3 \\
\hline Maspalomas & Gran Canaria & 270,7 & 12,6 & 4,7 & 25,2 & 9,3 & 232,9 & 86 \\
\hline Costa Adeje & Tenerife & 182,2 & 43,6 & 23,9 & 20,5 & 11,2 & 118,1 & 64,8 \\
\hline $\begin{array}{l}\text { Esquinzo- } \\
\text { Butihondo }\end{array}$ & Fuerteventura & 147,4 & 2,4 & 1,6 & 39 & 26,5 & 106 & 71,9 \\
\hline Abama & Tenerife & 127,3 & 0 & 0 & 14,4 & 11,3 & 112,9 & 88,7 \\
\hline Costa Teguise & Lanzarote & 123,5 & 41,8 & 33,9 & 4,9 & 4 & 76,8 & 62,2 \\
\hline Golf del Sur & Tenerife & 123,5 & 17,6 & 14,3 & 9,2 & 7,4 & 96,7 & 78,3 \\
\hline Costa Calma & Fuerteventura & 121,9 & 16,7 & 13,7 & 25,5 & 20,9 & 79,7 & 65,4 \\
\hline Tauro & Gran Canaria & 114,6 & 4,7 & 4,1 & 2,5 & 2,1 & 107,4 & 93,7 \\
\hline La Caleta & Tenerife & 92,4 & 5,3 & 5,7 & 0,9 & 1 & 86,2 & 93,3 \\
\hline Las Playitas & Fuerteventura & 68,5 & 1,1 & 1,6 & 19,5 & 28,5 & 47,9 & 69,9 \\
\hline $\begin{array}{l}\text { Puerto del } \\
\text { Carmen }\end{array}$ & Lanzarote & 55,4 & 12,3 & 22,2 & 0,4 & 0,7 & 42,7 & 77,1 \\
\hline Los Cristianos & Tenerife & 54,9 & 2,6 & 4,7 & 15,2 & 27,7 & 37,1 & 67,6 \\
\hline $\begin{array}{l}\text { Buenavista del } \\
\text { Norte }\end{array}$ & Tenerife & 52,7 & 2 & 3,9 & 1,8 & 3,4 & 48,9 & 92,8 \\
\hline Patalavaca & Gran Canaria & 46 & 15 & 32,5 & 0,8 & 1,7 & 30,3 & 65,8 \\
\hline $\begin{array}{l}\text { Puerto Rico- } \\
\text { Amadores }\end{array}$ & Gran Canaria & 45,6 & 9,8 & 21,4 & 15,7 & 34,4 & 20,2 & 44,2 \\
\hline Puerto Santiago & Tenerife & 39,3 & 14,9 & 38,0 & 6,8 & 17,2 & 17,6 & 44,8 \\
\hline $\begin{array}{l}\text { Puerto de la } \\
\text { Cruz }\end{array}$ & Tenerife & 36,4 & 8,9 & 24,4 & 1,1 & 3,1 & 26,4 & 72,6 \\
\hline Callao Salvaje & Tenerife & 31,1 & 8,6 & 27,5 & 1,2 & 4 & 21,3 & 68,5 \\
\hline Playa Paraíso & Tenerife & 30,5 & 6,4 & 21,1 & 10,7 & 35,3 & 13,3 & 43,7 \\
\hline $\begin{array}{l}\text { Puerto de } \\
\text { Mogán }\end{array}$ & Gran Canaria & 25,3 & 2 & 8 & 6,9 & 27,4 & 16,4 & 64,6 \\
\hline $\begin{array}{l}\text { Costa del } \\
\text { Silencio } \\
\end{array}$ & Tenerife & 21,6 & 7,5 & 34,6 & 0,6 & 2,9 & 13,5 & 62,5 \\
\hline Alcalá & Tenerife & 18,9 & 1 & 5,1 & 7,9 & 41,7 & 10,1 & 53,3 \\
\hline Las Américas & Tenerife & 18,6 & 0 & 0 & 7,8 & 41,8 & 10,8 & 58,2 \\
\hline
\end{tabular}


Tabla 2 (continuación)

DISTRIBUCIÓN DEL CRECIMIENTO DE LA SUPERFICIE OCUPADA POR EL USO RESIDENCIAL Y LA OFERTA DE ALOJAMIENTO EN LAS ÁREAS TURISTICAS DE CANARIAS (1998-2009)

\begin{tabular}{|c|c|c|c|c|c|c|c|c|}
\hline \multirow[t]{2}{*}{ Área turística } & \multirow[t]{2}{*}{ Isla } & \multirow{2}{*}{$\begin{array}{c}\text { Superficie } \\
\text { edificada } \\
\text { entre 1998- } \\
2009 \text { (en } \\
\text { hectáreas) }\end{array}$} & \multicolumn{2}{|c|}{$\begin{array}{c}\text { Superficie } \\
\text { ocupada por el } \\
\text { uso residencial }\end{array}$} & \multicolumn{2}{|c|}{$\begin{array}{c}\text { Superficie } \\
\text { ocupada por } \\
\text { la oferta de } \\
\text { alojamiento }\end{array}$} & \multicolumn{2}{|c|}{$\begin{array}{l}\text { Superficie ocupada } \\
\text { por otros usos* }\end{array}$} \\
\hline & & & $\begin{array}{c}\text { En } \\
\text { hectáreas }\end{array}$ & $\%$ & $\begin{array}{c}\text { En } \\
\text { hectáreas }\end{array}$ & $\%$ & En hectáreas & $\%$ \\
\hline $\begin{array}{l}\text { Solana- } \\
\text { Matorral }\end{array}$ & Fuerteventura & 11,1 & 0 & 0 & 0,5 & 4 & 10,7 & 95,9 \\
\hline Morro Jable & Fuerteventura & 9,6 & 2 & 20,8 & 0,3 & 2,8 & 7,3 & 76,4 \\
\hline Puerto Calero & Lanzarote & 6,2 & 1 & 15,9 & 3,6 & 58,4 & 1,6 & 25,5 \\
\hline Taurito & Gran Canaria & 5,4 & 0 & 0 & 1,2 & 21,6 & 4,2 & 78,3 \\
\hline Playa San Juan & Tenerife & 3,8 & 2,3 & 60,4 & 0 & 0 & 1,5 & 40,3 \\
\hline Los Gigantes & Tenerife & 1,4 & 0 & 1,7 & 0,1 & 7,1 & 1,3 & 91,4 \\
\hline $\begin{array}{l}\text { Patalavaca- } \\
\text { Arguineguín }\end{array}$ & Gran Canaria & 0,7 & 0 & 0 & 0 & 0,1 & 0,7 & 100 \\
\hline $\begin{array}{l}\text { Playa del } \\
\text { Inglés }\end{array}$ & Gran Canaria & 0,4 & 0 & 0 & 0 & 11,6 & 0,4 & 90 \\
\hline Marazul & Tenerife & 0 & 0 & 0 & 0 & 0 & 0 & 0 \\
\hline \multicolumn{2}{|c|}{ Total } & 2931,1 & 591,1 & 20,2 & 357,57 & 12,2 & 1982,42 & 67,6 \\
\hline
\end{tabular}

* Este apartado incluye a la oferta complementaria, viarios, zonas en obras y equipamientos públicos y privados (centros comerciales, plazas, parques, etc.).

Fuentes: Mapas topográficos 1:1.000 y 1:5.000 (GRAFCAN, 2009) / Mapa de ocupación del suelo (GRAFCAN, 2002) / Callejero Digital de Canarias (GRAFCAN, 2009). Elaboración propia.

del Suelo de 1975 y sucesivas reformas, que consolidó la competencia plena a los municipios en materia urbanística, sino también de la Ley 39/1988, de 28 de diciembre, Reguladora de las Haciendas Locales, que posibilitó que los municipios se dotasen de una estructura recaudatoria propia basada en la imposición sobre el suelo -en concreto, la capacidad de clasificarlo y calificarlo- en su doble mecanismo tributario de tenencia y plusvalías, con el fin de asegurar un grado aceptable de autonomía fiscal. Así, la proliferación de estas viviendas residenciales se revela como una importante fuente de ingresos económicos de tales corporaciones locales, sobre todo, vía recaudación del impuesto de bienes inmuebles, que contrarresta la reducida capacidad financiera de las Corporaciones Locales que, a su vez, es directamente proporcional a sus competencias en esta materia.

Íntimamente relacionado con lo anterior, otro factor que explica dicho crecimiento territorial de la residencialidad es la «obsesión» de la administración pública municipal de crear nuevos espacios turísticos como estrategia de rejuvenecimiento de las áreas turísticas consolidadas en consonancia con el habitual hábito de priorizar la inversión en nuevos crecimientos megalómanos (Burriel, 2008). Esta circunstancia se ha visto favorecida por la elevada, en términos relativos, oferta de suelo disponible en las «periferias» de las áreas turísticas o en otros municipios próximos, no consolidados turísticamente y susceptibles de albergar nuevos 
desarrollos residenciales vinculados al sistema turístico, con mejores condiciones de explotación y acordes a las actuales preferencias de la demanda; el resultado es un predominio de la estrategia de «tierra quemada», con el consiguiente consumo de suelo $\rightarrow$ amortización $\rightarrow$ abandono. Ello ha generado una situación cuando menos paradójica: mientras que las urbanizaciones residenciales más recientes «colonizan» nuevas áreas, las más antiguas, con peores condiciones de explotación y competitividad, debido a la mencionada obsolescencia, se localizan en los sectores de litoral más privilegiados desde el punto de vista del potencial turístico por razones paisajísticas, climáticas, de cercanía al mar (playas), etc.

Otro hecho que ha resultado decisivo para entender la proliferación de este tipo de residencialidad es que resulta compatible con la normativa vigente, en cuanto la admite excepcionalmente dentro de las zonas turísticas en dos tipos de situaciones: por un lado, en ámbitos consolidados o sectores especializados, cuando los nuevos desarrollos cumplan los mismos estándares de densidad y calidad de la edificación turística, de modo que se evita posibles disonancias entre ambos usos; y por otra, cuando ya coexistan el uso alojativo turístico con el residencial, permanente o temporal (DOT 12.5). Asimismo, resulta coherente con la permisibilidad contemplada en la DOT 19.2 en relación con la transformación del uso turístico en residencial en las zonas mixtas, en cuanto se llega a premiar con un incremento del $20 \%$ de la capacidad original cuando el uso alojativo se sustituya por el de vivienda protegida.

Por último, los proyectos residenciales constituyen una forma de inversión alternativa para un importante volumen de capital, local y foráneo. Ello ha favorecido una relación recursos propios-recursos ajenos relativamente baja, animada por la disponibilidad de financiación suficiente por parte del sistema bancario, con unos bajos tipos de interés, que, en muchos casos, ha sobrepasado los límites habituales de prudencia financiera, pensando más en la rentabilidad inmobiliaria de la inversión que en su futura viabilidad turística. Así, algunos factores acaecidos durante el tercer ciclo expansivo turístico, como el continuo descenso del coste del dinero y su mantenimiento a un nivel muy bajo, históricamente desconocido (Burriel, 2008), el incremento notable en los plazos medios de devolución de los préstamos hipotecarios (25, 40 o hasta 50 años), la elevación en la relación préstamo/valor, la práctica ausencia de restricciones crediticias (Fernández Tabales y Cruz Mazo, 2011), así como el tratamiento fiscal favorable de las plusvalías inmobiliarias, han favorecido el endeudamiento de las familias, bien para conseguir la vivienda deseada, bien para hacer muy interesante la inversión especulativa (Burriel, 2008), en este caso, en las áreas turísticas.

En relación con lo anterior, el conjunto de incentivos específicos de la fiscalidad canaria, en concreto, el ahorro fiscal vinculado con la Reserva para Inversiones en Canarias (RIC) contemplado en la Ley 19/1994, de 6 de julio, de Modificación del Régimen Económico y Fiscal de Canarias, ha favorecido esta expansión ex nova del uso residencial; como es sabido, su dotación posibilita la obtención de unas ventajas fiscales, en cuanto permite reducir la base imponible hasta un $90 \%$ de los beneficios no distribuidos en el Impuesto de Sociedades o del Impuesto sobre la Renta de las Personas Físicas por el importe que destinen de sus beneficios, sin previo pago de los mismos. En este sentido, la libertad interpretativa derivada de un desarrollo regulatorio insuficiente y dudoso, su rentabilidad fiscal y la posibilidad de invertir no sólo en la suscripción de inversiones financieras de instituciones públicas canarias o de títulos representativos del capital de las sociedades, sino también en la adquisición de activos fijos situados o recibidos en Canarias, han posibilitado la materialización de la RIC 
en suelo turístico, edificado o no. De este modo, ésta se convirtió en una fuente de financiación patrimonial para la construcción de viviendas residenciales, en cuanto se entendió contablemente como un proceso de adquisición de activos fijos.

\section{REFLEXIÓN FINAL}

En este trabajo se ha constatado que las nuevas formas de residencialidad identificadas en los espacios turísticos de Canarias han contribuido a la diferenciación de su estructura territorial y urbana en función de dos tipos de usos, el residencial y el turístico. Así, se ha corroborado la existencia de zonas donde los alojamientos turísticos se combinan con los usos residenciales, otras mixtas (turísticas y residenciales) con distintos tipos de intensidad y otras puramente residenciales (permanentes o con otras fórmulas de ocupación residencial distintas de la turística).

La aparición de estos procesos turísticos-residenciales en las áreas turísticas pone de manifiesto la competencia de los usos del suelo, con la consiguiente mezcla de factores de producción y del consumo en la estructura urbana (Williams y Hall, 2000). Asimismo, considerando que son consecuencia de una dinámica natural que se está consolidando en las áreas turísticas, tales procesos evidencian su comportamiento como sistemas abiertos y dinámicos, a la vez que dependientes de las condiciones de transformación, oportunidad o demanda de los mercados turísticos o inmobiliarios. Con ello, las áreas turísticas canarias se han configurado progresivamente como espacios en los que no existe un turista homogéneo, sino otros usuarios con necesidades y apetencias diferenciadas. En este sentido, los dos procesos de residencialidad identificados están provocando una especialización funcional de la estructura de las ciudades turísticas.

Por último, resulta preciso afrontar una reformulación de la normativa canaria en relación con estos procesos de residencialidad, sobre todo, en el momento actual en el que se intenta «reinventar» el modelo turístico de este destino turístico. Así, en lugar de «demonizarlos», la normativa debe asumirlos adecuadamente como una parte de su estructura, procediendo a su adecuada planificación y gestión, a la previsión de reservas de espacios libres, equipamientos y dotaciones conforme a los estándares obligatorios y adecuados a los usos y densidades resultantes, así como a la ejecución de las infraestructuras y servicios necesarios. Para ello se debe avanzar en el fomento de una urbanización que tenga suficiente capacidad para permitir la convivencia entre ambos usos; a este respecto, la capacidad del usuario a elegir su forma de disfrutar según su particular concepto de la experiencia turística debe ser un objetivo que hay que reconquistar.

\section{BIBLIOGRAFÍA}

ANTÓN, S. (1998): «La urbanización turística: De la conquista del viaje a la restructuración de la ciudad turística». Documents d'Anàlisi Geogràfica, no 32, 17-43.

BARRETTO, M. (2008): «Interfaces entre turismo e migrações. Uma abordagem epistemológica». Pasos: Revista de Turismo y Patrimonio Cultural, $\mathrm{n}^{\circ} 7$ (1), 1-11.

BELL, M. y WARD, G. (2000): «Comparing temporary mobility with permanent migration». Tourism Geographies, no 2 (1), 87-107. 
BENSON, M. y O'REILLY, K. (2009): «Migration and the search for a better way of life: A critical exploration of lifestyle migration». The Sociological Review, n 57(4), 608-625.

BETTY, Ch. y CAHILL, M. (1998): «Consideraciones sociales y sanitarias sobre los inmigrantes británicos mayores en España, en particular los de la Costa del Sol». Migraciones, $\mathrm{n}^{\mathrm{o}} 3,83-115$.

BREUER, T. (2005a): «Alemanes de la Tercera Edad en Canarias» en La inmigración de europeos retirados en España (Rodríguez, V. et al., ed.). Madrid, CSIC.

BREUER, T. (2005b): «Características del turismo residencial de alemanes jubilados: resultados de una encuesta realizada en las Islas Canarias», en Turismo residencial y cambio social: Nuevas perspectivas teóricas y empíricas (Mazón, T. y Aledo, A. eds.). Alicante, Aguaclara, 363-374.

BURRIEL, E. L. (2008): «La década prodigiosa del urbanismo español (1997-2006)», Scripta Nova: Revista electrónica de geografía y ciencias sociales, vol. 12, nº 270 (64). Disponible en http://www.ub.edu/geocrit/-xcol/383.htm

CAPOTE, L. (2012): «La segunda vivienda: El timesharing como opción de alojamiento vacacional». LandAS | International Journal of Land Law \& Agricultural Science, $\mathrm{n}^{\circ} 7$, 45-50.

CASADO, M.A y RODRÍGUEZ, V. (2002): «La migración internacional de retirados en España: limitaciones de las fuentes de información», Estudios Geográficos, nº 248/249, 533-538.

CORTINA, F.; MARTÍNEZ, A. y VARELA, B. (2002): «Aproximación a la investigación del alojamiento privado de uso turístico». Estudios Turísticos, n 151, 87-97.

DÍAZ, Ma . C.; MARTÍN, J. F.; PULIDO, T. y VERA, J. R. (1985): «Recursos humanos, empleo y paro en el sector turístico canario», en IV Jornadas de Estudios Económicos Canarios. Tomo V. Secretariado de Publicaciones de la Universidad de La Laguna, pp. 321-341.

DOMÍNGUEZ, J. (1996): La inmigración extranjera en la provincia de Las Palmas. Las Palmas de Gran Canaria. CIES-La Caja de Canarias.

DOMÍNGUEZ, J., GONZÁLEZ, J. y PARREÑO, J.M. (2008): «Transformaciones recientes en barrios turísticos maduros. Los casos de Palma de Mallorca y Las Palmas de Gran Canaria». Scripta Nova. Revista electrónica de Geografía y Ciencias Sociales, vol. XII, nº 170.

EXCELTUR-DELOITTE (2005): Impactos sobre el entorno, la economía y el empleo de los distintos modelos de desarrollo turístico del litoral mediterráneo español, Baleares y Canarias. Madrid, Exceltur.

FEO, F. (2001): «Los campos de golf en España y sus repercusiones en el sector turístico». Cuadernos de Turismo, $\mathrm{n}^{\mathrm{o}}$ 7, 55-66.

FERNÁNDEZ, A. y CRUZ, E. (2011): «Territorio y actividad constructora: del tsunami a la crisis. Factores explicativos y propuesta de indicadores a escala municipal en Andalucía», en Boletín de la Asociación de Geógrafos Españoles, nº 56, 79-110.

FERRER, R. I.; RIBERA, D. y REIG, A. (1997): Jubilados en la costa alicantina. Alicante, Publicaciones de la Universidad de Alicante.

GONZÁLEZ, F. (2008): «El papel de los destinos turísticos en la transformación sociodemográfica del litoral mediterráneo español», Boletín de la Asociación de Geógrafos Españoles, no 47, 79-107. 
GONZÁLEZ, M., LEÓN, C. y PADRÓN, N. (2006): «Obsolescencia y políticas de renovación medioambiental en el sector turístico». Cuadernos económicos de ICE, $\mathrm{n}^{\circ} 71$, 153-176.

GUSTAFSON, P. (2009): «Your home in Spain: residential strategies in international retirement migration» en Lifestyle Migration: Expectations, Aspirations and Experiences (Benson, M. y O’Reilly, K. eds.). Ashgate. Surrey.

HUETE, R. y MANTECÓN, A. (2010): «Los límites entre el turismo y la migración residencial. Una tipología». Papers, revista de Sociología, nº 95/3, 781-801.

HUETE, R., MANTECÓN, A. y MAZÓN, T. (2008): «¿De qué hablamos cuando hablamos de turismo residencial?». Cuadernos de Turismo, $\mathrm{n}^{\circ}$ 22, 101-121.

KING, R.; WARNES, A. y WILLIAMS, A. (2000): Sunset lives: British retirement migration to the Mediterranean. Oxford. Berg.

LÓPEZ, J; MÒDENES, J.A \& YÉPEZ, B. (2007): «Los usuarios de residencias secundarias en España: perfiles regionales», Boletín de la Asociación de Geógrafos Españoles, n 45 , 307-325.

MANTECÓN, A. (2008): «Procesos de urbanización turística: aproximación cualitativa al contexto ideológico». Papers. Revista de Sociología, nº 89, 127-144.

MARTÍN, J-F. (1984): «Desarrollo demográfico y crecimiento espacial de las áreas turísticas de la isla de Tenerife». Anuario de Estudios Atlánticos, nº 30, 317-340.

MAZÓN, T. (2002): «El nuevo modelo turístico en las sociedades desarrolladas». Papers de Turisme, $\mathrm{n}^{\circ} 29,90-107$.

MAZÓN, T (2007): «El perfil del turista residente de la Unión Europea en la Comunidad Valenciana», en Turismo en los espacios litorales (López, D., ed.). Valencia, Tirant lo Blanch, 263-291.

MAZÓN, T. y ALEDO, A. (2005): «El dilema del turismo residencial: ¿turismo o desarrollo inmobiliario?» en Turismo residencial y cambio social: nuevas perspectivas teóricas y empíricas (Mazón, T. y Aled, A., coord.), Alicante, CAM-FRAX-Universidad de Alicante, 13-30.

NAVARRO, E. (2006): «Proceso de crecimiento e intensificación de usos en los destinos turísticos consolidados» en Turismo y cambio territorial: ¿eclosión, aceleración, desbordamiento? (Lacosta, A.J., coord.). Zaragoza, Prensas Universitarias de Zaragoza, 319-350.

OBIOL, E. y PITARCH, M ${ }^{\mathrm{a}}$ D. (2011): « El litoral turístico valenciano. Intereses y controversias en un territorio tensionado por el residencialismo». Boletín de la Asociación de Geógrafos Españoles n ${ }^{\circ} 56,177-200$.

O'REILLY, K. (2007): «Intra-European Migration and the Mobility-Enclosure Dialectic». Sociology, nº 41 (2), 277-293.

PARREÑO, J. M. (2006): «Turismo residencial de europeos y consecuencias inmobiliarias en Canarias», en VIII Coloquio y jornadas de campo de Geografía Urbana. Universitat de les Illes Balears / Asociación de Geógrafos Españoles, 383-398.

PICORNELL, M.; AMER, M. y ARROM, J.M. (2006): «Eliminación y limitación del crecimiento de plazas de alojamiento turístico a favor del crecimiento continuado de plazas turísticas residenciales en las Illes Balears» en Turismo y cambio territorial: ¿eclosión, aceleración, desbordamiento? (Lacosta, A.J., coord.). Zaragoza, Prensas universitarias de Zaragoza, 561-572. 
RAYA, P. y BENÍTEZ, J.J. (2002): «Concepto y estimación del turismo residencial: aplicación en Andalucía», Papers de Turisme, nº 31-32, 67-89.

REQUEJO, J. (2008): «¿Por qué lo llaman turismo cuando quieren decir promoción inmobiliaria?», Destinos turísticos: viejos problemas, ¿nuevas soluciones? X Coloquio de Geografía del Turismo, Ocio y Recreación (Troitiño, M.A., Saíl, J. y García, Mª), Asociación de Geógrafos Españoles, 653-662.

RODRÍGUEZ, V. (2004): «Turismo residencial y migración de jubilados», Las nuevas formas de turismo. Monográfico de la revista Mediterráneo Económico (Aureoles, J., coord.). Almería, Cajamar, 233-253.

SALVÀ, P. (2005): «Procesos, pautas y tendencias del turismo residencial en las Islas Baleares: ¿inmigrantes de lujo o turistas de larga estancia?» en Turismo residencial y cambio social. Nuevas perspectivas teóricas y empíricas (Mazón, T. y Aledo, A., eds.). Alicante, Aguaclara, 281-302.

SANTANA TURÉGANO, M. (2005): «Turismo, empleo y desarrollo». Papers, revista de Sociología, $\mathrm{n}^{\circ} 77,79-104$.

SIMANCAS, M. R. (2012): «Evaluando políticas públicas de renovación de destinos turísticos maduros: el proceso de reconversión turística de Canarias», en Renovación y restructuración de destinos en áreas costeras. Marco de análisis, procesos, instrumentos y realidades (Vera, F. y Rodríguez, I. eds.). Colección: Desarrollo Territorial, 11. Universitat de València, 163-200.

SIMANCAS, M. R.; GARCÍA, J. I.; DORTA, A. y FALERO, R. A. (2011): «El impacto territorial de la moratoria turística de Canarias» en Urbanismo expansivo: de la utopía a la realidad. XXII Congreso de Geógrafos Españoles (Gonzálvez, V. y Marco, J. A., ed.). Alicante, Asociación de Geógrafos Españoles / Colegio de Geógrafos de España / Universidad de Alicante, 715-726.

SIMANCAS, M.R.; HORCAJADA, T. y GARCÍA, J. I. (2009): «La modelización territorial de los procesos de residencialidad en áreas turísticas consolidadas de litoral: el caso de Costa Adeje (Tenerife)» en Turismo, urbanización y nuevos estilos de vida. Las nuevas formas de movilidad residencial (Mazón, T., Huete, R. y Mantecón A., ed.). Barcelona, Icaria Editorial, 315-333.

TORRES, E. (2003): «El turismo residenciado y sus efectos en los destinos turísticos». Estudios Turísticos, $\mathrm{n}^{\circ}$ 155-156, pp. 45-70.

VALENZUELA, M. (1988): «La residencia secundaria. Mito social y conflicto urbanístico en los espacios turísticos-recreativos». Urbanismo: Revista del Colegio Oficial de Arquitectos de Madrid, $\mathrm{n}^{\mathrm{o}} 4$.

VALENZUELA, M. (2006): «Cambio turístico y nuevos horizontes residenciales» en VIII Coloquio y jornadas de campo de Geografía Urbana. Universitat de les Illes Balears / Asociación de Geógrafos Españoles, 261-302.

VARELA, B., LÓPEZ, A. y MARTÍNEZ, A. (2003): «Primeras aproximaciones al estudio estadístico del alojamiento privado con fines turísticos desde una perspectiva de oferta», Estudios Turísticos, $\mathrm{n}^{\circ}$ 155-156, pp. 87-112.

VERA, J.F.; LÓPEZ, F.; MARCHENA, M. y ANTÓN, S. (2011): Análisis territorial del turismo y planificación de destinos turísticos. Tirant lo Blanch. Valencia. 
VERA, F. (2005): «El auge de la función residencial en destinos turísticos del litoral mediterráneo: entre el crecimiento y la renovación». Papers de turisme, n 37-38, 95-114.

VERA, F. y BAÑOS, C.J. (2004): «Turismo, territorio y medio ambiente», Papeles de Economía Española, no 102, pp. 271-286.

VERA, J. F.; MARCHENA, M. (1996). «El modelo turístico español: perspectiva económica y territorial» en Introducción a la economía del turismo en España (Pedreño, A., dir.). Madrid, Editorial Civitas, 27-364.

VILLAR LAMA, A. (2011): Territorio, turismo y paisaje: el proceso de urbanización en el litoral de Andalucía. El papel de los campos de golf. Sevilla, Consejería de Turismo, Comercio y Deporte. Disponible en: http://www.juntadeandalucia.es/turismocomercioydeporte/publicaciones

WILLIAMS, A. y HALL, C. M. (2000): «Tourism and migration: New relationships between production and consumption». Tourism Geographies, nº 2 (1), 5-27.

ZAPATA, V. (2002): La inmigración extranjera en Tenerife. Santa Cruz de Tenerife, Cabildo Insular de Tenerife. 
